\title{
Simultaneous assimilation of water levels from river gauges and satellite flood maps for near-real time flood mapping
}

\author{
Antonio Annis ${ }^{1,2}$, Fernando Nardi ${ }^{1,3}$, and Fabio Castelli ${ }^{2}$ \\ ${ }^{1}$ WARREDOC, University for Foreigners of Perugia, Perugia Italy \\ ${ }^{2}$ DICEA, University of Florence, Florence, Italy \\ ${ }^{3}$ Institute of Water and Environment, Florida International University, Miami, USA
}

Correspondence: Antonio Annis (antonio.annis@unistrapg.it)

\begin{abstract}
Hydro-meteo hazard Early Warning Systems (EWSs) are operating in many regions of the world to mitigate nuisance effects of floods. EWSs performances are majorly impacted by the computational burden and complexity affecting flood prediction tools, especially for ungauged catchments that lack adequate river flow gauging stations. Earth Observation (EO) systems may surrogate to the lack of fluvial monitoring systems supporting the setting up of affordable EWSs. But, EO data, constrained by spatial and temporal resolution limitations, are not sufficient alone, especially at medium-small scales. Multiple sources of distributed flood observations need to be used for managing uncertainties of flood models, but this is not a trivial task for EWSs. In this work, a near real-time flood modelling approach is developed and tested for the simultaneous assimilation of both water level observations and EO-derived flood extents. An integrated physically-based flood wave generation and propagation modelling approach, that implements a Ensemble Kalman Filter, a parsimonious geomorphic rainfall-runoff algorithm (WFIUH) and a Quasi-2D hydraulic algorithm, is proposed. A data assimilation scheme is tested that retrieves distributed observed water depths from satellite images to update 2D hydraulic modelling state variables. Performances of the proposed approach are tested on a flood event for the Tiber river basin in central Italy. The selected case study shows varying performances depending if local and distributed observations are separately or simultaneously assimilated. Results suggest that the injection of multiple data sources into a flexible data assimilation framework, constitute an effective and viable advancement for flood mitigation tackling EWSs data scarcity, uncertainty and numerical stability issues.
\end{abstract}

\section{Introduction}

Floods represent one of the most costly and deadly natural disasters (EM-DAT, 2016), affecting annually on average more than 21 million people and producing economic loss greater than US \$ 100 billion (Desai et al., 2015). The ability to understand and predict floods represent a crucial assets of river basin management strategies (Knight and Shamseldin, 2005). Numerical simulations of flood scenarios are used for proper design of structural (e.g. levees, diversion channels, dams, etc.) and nonstructural mitigation measures (e.g. land use regulations, flood zoning, flood proofing, flood forecasting and warning, disaster prevention, preparedness and response) (Thampapillai and Musgrave, 1985). Early Warning Systems (EWSs) are nowadays increasingly used for timely detection of flood events (Kundzewicz, 2013). 
EWSs generally require integrated geospatial modelling of floodplain domains supporting integrated topographic-hydrologichydraulic modelling chains to produce inundation predictions (Krzhizhanovskaya et al., 2011). Digital terrain models (DTMs), rainfall and runoff observations are required by EWSs for flood nowcasting and forecasting (Grimaldi et al., 2016). Flood models are computer- and data-intensive applications with input data requirements (i.e. accuracy and distribution) that are often unmet, especially river flow observations (Wing et al., 2020). As a result, EWSs suffer of several concurring uncertainties associated to boundary conditions, numerical parameterizations and discretizations of floodplain features and processes (Demeritt et al., 2007). The calibration and validation of flood models for data-scarce regions constitute, thus, a significant challenge for flood modellers that are often compelled to understand and manage parameter and output uncertainties (Moradkhani et al., 2005; Hostache et al., 2011; Liu and Gupta, 2007).

Data Assimilation (DA) methods represent effective means to reduce these uncertainties (Cloke and Pappenberger, 2009). DA improve EWS performances by adjusting flood model parameters, input, output or state variables using available observations. Stream gauge observations are the most used for updating hydrologic (McLaughlin, 2002; Moradkhani et al., 2005; Liu and Gupta, 2007) and hydraulic (Madsen and Skotner, 2005; Neal et al., 2007) model variables. However, single (or sparse) gauging stations generally fail to provide accurate flow observations during extreme events due to the distributed complex nature of flood processes (e.g. split flows, tributary junctions, overbank flow conditions; bridge overtopping). This is particularly critical for EWSs covering secondary ungauged river networks (Biancamaria et al., 2011; Mason et al., 2012). To tackle this issue, in the last ten years, Earth Observation (EO) data were used to inject water altimetry observations in DA frameworks for updating flood models, usually adopting radar Synthetic Aperture Radar (SAR) technologies and 1D hydraulic routing algorithms (Andreadis et al., 2007; Matgen et al., 2007; Neal et al., 2009; Hostache et al., 2010; Matgen et al., 2010; Giustarini et al., 2011; García-Pintado et al., 2013; Mason et al., 2012; Andreadis and Schumann, 2014). On the other hand, SAR-derived inundation extent mapping techniques were tested to provide spatially distributed information to support near real-time flood detection services (Martinis et al., 2015; Pierdicca et al., 2009). Notable examples of DA research exist proving the value of assimilating satellite images for diverse purposes e.g. for optimizing a lumped friction parameter of a 2D flood model (Lai et al., 2014); in large scale hydrologic model with a flow routing function for flood forecasting (Revilla-Romero et al., 2016); or in a high resolution hydraulic model for near-real time flood forecasting (Hostache et al., 2018). Hostache et al. (2018) underlined opportunities of SAR images, overcoming visibility issues of optical sensors due to clouds, but also stressing some limitations of water altimetry approaches. In particular, the need of high resolution topographic data, challenging pre-processing and hydraulic modelling development make SAR-derived DA approaches hard to replicate and to be applied at varying scales (Mason et al., 2012; Wood et al., 2016). Hostache et al. (2018) analyzed improved performances of EWSs in reducing water level estimation errors if compared to Open Loop (OL) simulations (i.e. not updating flood state variables with observations).

In this work, a novel DA framework - supported by both local water level observations from stage gauges and spatially distributed information gathered from satellite images - is proposed and tested. This research seeks to develop a more flexible DA 
scheme that may value all available sources of observations for distributed flood modelling updates. The aim of this work is to mitigate flood prediction uncertainties by combining heterogeneous data and an integrated topographic-hydrologic-hydraulic modelling approach, while maintaining inundation forecasting robustness, scalability and numerical stability. In achieving this goal, novel scientific advances and technical challenges of EO-driven DA approaches for flood prediction are investigated and in particular: A methodology for updating the state variable of a hydraulic model for distributed flood routing in floodplain domains; the gathering of spatially distributed water level observations by means of flood extension processing and detection from satellite images. This work conceptualizes and tests a novel framework for updating state variables of a Quasi-2D hydraulic model adopting the Ensemble Kalman Filter (EnKF) method to take advantage of observations gathered from heterogeneous sources. The Tiber river basin in central Italy is selected as case study that was recently the subject of flood events at the meso-scale level (approximately $100 \mathrm{~km}^{2}$ of flood-prone domain), to investigate on improved flood modelling performances.

The paper is organized as follows: Section 2 describes the adopted hydrologic, hydraulic, and DA modelling methodologies. Section 3 illustrates the case study, the available data and the proposed DA implementation procedure. Section 4 discusses case study results, while section 5 provides conclusive remarks underlining advantages, limitations and suggested future developments of this research.

\section{Methods}

\subsection{Hydrologic and 2D hydraulic modelling}

The physically based Quasi-2D hydraulic model (FLO-2D, O'brien et al., 1993) was selected for flood wave routing and propagation. In fact, the regular grid mesh of its computational domain and the simple open format of the input and output files make the model suitable to be integrated in a Data Assimilation framework. The model solves the differential form of the dynamic wave approximation of the de Saint Venant equations with a central, finite difference numerical scheme. The numerical solution is applied along the river flowpath for in-channel 1D flood wave routing and for out-of-channel unconfined flood propagation considering 8 potential flow directions in a bi-dimensional (2D) domain. Channel and floodplain grid cells are assigned an absolute elevation, defining the floodplain and channel top surface topography. Channel conveyance capacity is considered by assigning to each cell a cross section with top banks associated to the corresponding floodplain cell elevation. The channel-floodplain flow exchange is simulated for taking into account over-bank and return flows within the riverine system. River and floodplain bridges, culverts, levees and any obstruction within the simulation domain are simulated in FLO-2D by means of rating curve, width and areal reduction factors. Two main boundary conditions were defined for the application of the Quasi-2D model: a) the floodplain domain extent; b) the hydrologic forcing from upstream for both the main river stem (i.e. source node) and for the tributaries.

The floodplain computational domain a) is associated to the maximum potential inundation extent. A DTM-based hydrogeomorphic floodplain mapping approach following Nardi et al. (2006) and Nardi et al. (2013) was selected for characterizing 
this boundary condition. The selected GFPLAIN hydrogeomorphic floodplain extent model identifies the floodplain buffer domain by employing hydrological scaling laws to assess maximum flood energy gradients using the upstream contributing area as scaling factor (Nardi et al., 2018,Annis et al., 2019). GFPLAIN allows to restrict the computational domain for the 2D flood model application optimizing the DA approach implementation. Further details of the computational domain for the specific case study are described in Section 3.2.

The upstream and tributary flow boundary conditions b) are derived by stage gauge observations (where available) or from the application of a rainfall-runoff model (considering rainfall observations are available at river basin scale). A parsimonious hydrological model tailored for ungauged basins was selected to simulate the hydrologic forcing following Grimaldi et al. (2012) approach. This rainfall-runoff approach is based on the application of the geomorphic characterization of the Istantaneous Unit Hydrograph (IUH) adopting the WFIUH method (Mesa and Mifflin, 1986). In the WFIUH the shape of the river basin response to the rainfall forcing is associated to rainfall drop residency time distribution. The WF distribution may be expressed estimating the flow paths and associated to each flow path the travel time to reach the outlet (Rodriguez-Iturbe and Rinaldo, 1997). The WFIUH distribution is, thus, estimated by applying channel $\left(v_{c}(x)\right)$ and hillslope $\left(v_{h}(x)\right)$ velocities to their corresponding flow paths $L_{c}(x)$ and $L_{h}(x)$ :

$W F I U H(t)=\frac{L_{c}(x)}{v_{c}(x)}+\frac{L_{h}(x)}{v_{h}(x)}$

The WFIUH distribution can be estimated using the DTM as main input information and applying terrain analysis algorithms for river basin hydrologic processing (pit removal- Jenson and Domingue, 1988-, flow direction, flow accumulation - Tarboton et al., 1991) to estimate flow paths at the basin scale. Channel velocities are considered constant according to Grimaldi et al. (2012). The hillslope velocity distributions $u_{h}$ are calculated according to NRCS (1997) as a function of the local slope and land use (Haan et al., 1994; McCuen, 2009). The adopted runoff modelling approach also consider distributed rainfall input and related infiltration losses using the SCS-CN method (Cronshey, 1986). Input rain gauge observations are interpolated using the Thiessen polygon methodology to properly assess distributed rainfall input for the hydrologic model (Thiessen, 1911).

\subsection{Data Assimilation (DA) framework}

A scheme of the whole DA framework with the reference of the related sections is illustrated in Figure 1. The Ensemble Kalman Filter method (EnKF- Evensen, 2003) was selected for DA application on the proposed 2D hydraulic modelling approach. EnKF, widely used in literature for DA, was selected for its efficiency in dealing with the significant non-linear flood dynamics (Reichle et al., 2002). The EnKF model is a sequential DA method that estimates the model state at time $t+1$ $\left(h_{t+1}\right)$ based on the observations at the time steps in which they are available. The DA process is characterized by two steps: the forecast step and the updated step, whose variables will be represented respectively with the superscript - for forecasting and + for updating. The method is based on ensemble generations: the forecast (a priori) state error covariance matrix $P_{t+1}^{-}$is approximated propagating the ensemble of the model states, according to the model errors expressed as a noise term $w_{t+1}$, from 
the previous time step; at the same time, an ensemble of observations $y_{t+1}$ at each update time is generated according to their error distribution introducing the noise term $\eta_{t+1}$. The updated probability density function $(p d f)$ of the model states is given by a combination between data likelihood and forecast $p d f$ of the model states by means of Bayesian update. Specifically, the posterior estimate of the $i$-element of the ensemble $h_{t+1}^{i+}$ is calculated using the observation $y_{t+1}^{i}$ performing a linear correction with the Kalman filter to the forecast state ensemble members:

$$
h_{t+1}^{i+}=h_{t+1}^{i-}+K_{t+1}\left[y_{t+1}^{i}-\left(H\left(h_{t+1}^{i-}, \theta\right)+v_{t+1}^{i}\right)\right] \quad K_{t+1}=\frac{P_{t+1}^{-} H_{t+1}^{T}}{H_{t+1} P_{t+1}^{-} H_{t+1}^{T}+R_{t+1}^{y}}
$$

where $K_{t+1}$ is the Kalman gain matrix, $H(\ldots)_{t+1}$ is a propagator relating the state variables to the measured variables and provides the expected value of the output given the model state, $v_{t+1}^{i}$ is the sample of the observation errors, $R_{t+1}^{y}$ is the variance of the observation error.

The performance of the ensemble forecast is influenced by the spread of the ensemble (Murphy, 1988; Anderson, 2001), but also by the ensemble size. The size has to be sufficiently large to represent a statistically significant sample, but at the same time it has to be computational efficient considering the purpose of the application (e.g. near-real time updating of a flood model). In this work, the approach proposed by Anderson (2001) was selected. Therefore, the optimal ensemble size was selected to reach to a Normalized RMSE Ratio (NRR) equal to one.

The EnKF method application for the proposed Quasi-2D distributed hydraulic model was developed as follows. The state variable $h_{t+1}$ is associated to the water depth in a specific point of the computational floodplain domain. In case the observation is a stage gauge measurement, the state variable position is determined by identifying the closest channel cell. In case the observations is gathered from a satellite image, the EnKF method is applied to both the channel and the floodplain cells falling within the observation domain. The model error $w_{t+1}$ is estimated considering the uncertainties related to the input forcing $I_{t+1}$ and the model parameters as explained in Section 2.2.3. The observation $y_{t+1}$ is a water depth value gathered indirectly by the sensor. For this reason, the observation transition operation $H$ introduced in Eq. (2) is an identity matrix, being a direct relationship between state variables and observations.

\subsubsection{Model updating}

\subsubsection{Stage gauges observations}

The updating of the water levels from Static Sensors $(S H)$ located at fixed infrastructures (e.g. bridges, weirs) in the proposed DA framework aims to correct both the channel and the floodplain water levels taking into account the interlinked channelfloodplain dynamics. The channel cell is here used to infer the water level information to floodplain cells in the proximity of the observation applying the EnKF. If the difference between the observed and the simulated water level is significant (e.g. 
more than 1 meter), numerical surging may occur. To avoid surging, a gain function is applied adopting an approach similar to Madsen and Skotner (2005):

$g\left(x_{k}\right)=A \cdot \exp \left(-\frac{1}{2}\left(\frac{g^{\prime}\left(x_{k}\right)}{1 / 3}\right)^{2}\right)$

where $g\left(x_{k}\right)$ is the gain assigned to the $k$-cell, $A$ is the gain amplitude (assumed equal to 1), and the $g^{\prime}\left(x_{k}\right)$ term is expressed as:

$g^{\prime}\left(x_{k}\right)= \begin{cases}\frac{x_{o b s}-x_{k}}{x_{o b s}-x_{u c}}, & x_{u c} \leq x_{k} \leq x_{o b s} \\ \frac{x_{k}-x_{o b s}}{x_{d c}-x_{o b s}}, & x_{o b s} \leq x_{k} \leq x_{d c}\end{cases}$

where $x_{o b s}, x_{k}, x_{u c}, x_{d c}$ are the linear coordinates along the channel of respectively the cell with the observation, the $k$ cell to be updated, the upstream and downstream bounds for the gain function. The last two terms allow to consider how far the updating could be inferred to correct the flood water profile. Varying downstream or upstream model updates may be implemented to avoid the propagation of local inaccuracies of the model. The gain function also allows to inject into the DA more than one observation for the same time step. The bounds of the gain for a $k$-cell are limited by the position of the closest stage gauge cells. Figure 2 provides a scheme of the adopted channel and floodplain model updating, depicting the propagation of the gain function upstream and downstream as respect to the observation point. Furthermore, in order to properly assimilate more than one stage gauge observation, the channel segment (and its floodplain) that fall between two different simultaneous stage observations, are updated weighting the observation values by a multiplying factor expressed as the inverse of the distance between the observation and target channel cells. The water level correction for the $k$-cell $\Delta H\left(x_{k}\right)$ is given by the following expression:

$\Delta h\left(x_{k}\right)=\frac{\Delta h\left(x_{o b s, u}\right) \cdot g\left(x_{k, u}\right) \cdot \frac{1}{x_{k}-x_{o b s, u}}+\Delta h\left(x_{o b s, d}\right) \cdot g\left(x_{k, d}\right) \cdot \frac{1}{x_{o b s, d}-x_{k}}}{\frac{1}{x_{o b s, d}-x_{o b s, u}}}$

where $\Delta h\left(x_{o b s, u}\right)$ and $\Delta h\left(x_{o b s, d}\right)$ are the water level updates respectively in the upstream and downstream stage gauges, $g\left(x_{k, u}\right)$ and $g\left(x_{k, d}\right)$ are the gains relative respectively to the upstream and downstream observation, $x_{o b s, u}$ and $x_{o b s, d}$ are the linear coordinates along the channel of respectively the upstream and downstream cells of the observation. When the gain function is propagated upstream and the water level correction is positive, a water profile counterslope may be inferred, causing a numerical instability issue in the hydraulic model. To avoid this issue, a further condition was imposed: the absolute water level in the channel cell $h_{a b s}^{+}\left(x_{k}\right)$, cannot be lower than the adjacent downstream channel cell $h_{a b s}^{+}\left(x_{k+1}\right)$ :

$h_{a b s}^{+}\left(x_{k}\right)= \begin{cases}h_{a b s}^{-}\left(x_{k}\right)+\Delta h\left(x_{k}\right), & h_{a b s}^{+}\left(x_{k}\right) \geq h_{a b s}^{+}\left(x_{k+1}\right) \\ h_{a b s}^{+}\left(x_{k+1}\right), & h_{a b s}^{+}\left(x_{k}\right)<h_{a b s}^{+}\left(x_{k+1}\right)\end{cases}$ 
The proposed model updating procedure is invoked at each time step when one or more observations become available. The hydraulic simulation is stopped saving distributed floodplain water levels and volume conservation to binary files. Then, the EnKF is applied and the water depth corrections are applied to update model states in the binary files.

\subsubsection{Satellite image observations}

The assimilation of flow depths derived from satellite image processing is developed following 3 main steps:

1. Flood detection from satellite image(s);

2. Comparison of the flood extent detected from the satellite image with the ensemble of flood extents simulated by the hydraulic model;

3. Derivation of the water depth distribution related to the satellite image starting from the ensemble of the water elevation distributions of the hydraulic model.

1) The proposed methodology aims to be applicable to both multispectral and SAR images to increase the take advantage of all available satellite observations of a flood event. Considering multispectral images suffer of significant limitations due to cloud cover and light conditions, the Modified Normalized Difference Water Index (MNDWI) proposed by Xu (2006) is applied. The $M N D W I$ is expressed as:

$M N D W I=\frac{\rho_{b g}-\rho_{b m}}{\rho_{b g}+\rho_{b m}}$

where $\rho_{b g}$ and $\rho_{b m}$ are the reflectance indices of respectively the Green and Mid Infra Red (MIR) bands. For SAR images, the image histogram thresholding methodology is implemented following Brivio et al. 2002.The satellite image processing is optimized by limiting the spatial extent to the pre-identified floodplain domain estimated as described in 2.1.

2) The satellite detected water extension is, then, compared with the flood extension ensemble simulated by the hydraulic model $(H M)$ at the time step of the satellite image's acquisition date. In order to avoid the impact of resolution issue on the comparison, the simulated flood raster is downscale at the same resolution of the satellite image by following this procedure:

- The water surface elevation is interpolated at the satellite image resolution by applying the Kriging method using the maximum floodplain extent polygon ;

- The interpolated Water Surface Elevation (WSE) is intersected with a high resolution DTM to flag positive values as potentially flooded. 
The two raster flood maps (Water extension from $S I$ and from $H M$ ) are, then, quantitatively compared by applying the

$F=\frac{A}{A+B+C}$

For the generic $k$-cell pertatining to the hydraulic modelling domain, the satellite-derived indirectly observed water depth $h_{o, t}^{k}$ at the time $t$, is expressed as:

$h_{o, t}^{k}=h_{m, i_{1}, t}^{k} \cdot \frac{F_{i_{1}}}{F_{i_{1}}+F_{i_{2}}}+h_{m, i_{2}, t}^{k} \cdot \frac{F_{i_{2}}}{F_{i_{1}}+F_{i_{2}}}$

where $F_{i_{1}}$ and $F_{i_{2}}$ are the two best fitting flood maps from the ensemble of the $H M$ compared to the flood extent from the $S I, h_{m, i_{1}, t}^{k}$ and $h_{m, i_{2}, t}^{k}$ are their related the flow depths of the $k$-cell at time $t$.

\subsubsection{Model errors}

The uncertainty related to model errors are numerically managed within the proposed DA by perturbing:

- the hydrologic forcing input given by the upstream static sensors and the rainfall-runoff modelling output;

- the hydraulic model parametrization associated to channel roughness expressed by the distributed Manning coefficients.

In both cases the flow discharge values at time $t$ of the $s$-input for the $i$-element of the ensemble are expressed using the following equation (Weerts and El Serafy, 2006):

$Q_{s, t}^{i}=Q_{s, t}^{\text {true }} \cdot \gamma+N\left(0, R_{s}\right) \quad R_{s}=\left(\alpha_{s} \cdot Q_{s, t}^{\text {true }}\right)^{b}$

where $Q_{s, t}^{\text {true }}$ is the streamflow value by the $s$-input at time $t, \gamma$ is a parameter that accounts for the uncertain estimation of the synthetic discharge, $N\left(0, R_{s}\right)$ is a noise term normally distributed with zero mean and a given variance $R_{s}, \alpha_{s}$ is the coefficient of variation related to the uncertainty of the discharge, $b$ is an exponent related to the type of input flow. Equation 10 infers the intuitive principle that high discharge values are more uncertain than low values.

The uncertainty related to discharge observations gathered from static sensors (SG) is the sum of two components (Clark et al., 2008): the estimation of the water level from the static sensor reading ( $E W L)$; the conversion of the water level into discharge using the fluvial cross section rating curve $(E R C)$. In this work, the coefficient of variation related to the static sensor was set to $\alpha_{S G}=0.1$, where $\alpha_{E W L}=0.1$ (Weerts and El Serafy, 2006; Clark et al., 2008; Rakovec et al., 2012) and $\alpha_{E R C}$ is considered negligible as respect to the $\alpha_{E W L}$ (Baldassarre and Montanari, 2009). The coefficient of variation related to the input provided by the hydrologic model $\left(\alpha_{I}\right)$ can be derived from a validation analysis of the hydrologic model calculating 
https://doi.org/10.5194/hess-2021-125

Preprint. Discussion started: 8 April 2021

(c) Author(s) 2021. CC BY 4.0 License.

the distribution of the simulated flow errors. For both uncertainties related to $S G$ and $I, \gamma$ and $b$ values were imposed equal to 1 .

In addition to the uncertainty due to the hydrologic forcing, the uncertainty related to the channel roughness is also considered as follows (Clark et al., 2008; McMillan et al., 2013):

$p_{s}^{i}=p_{s}+U\left(-\epsilon_{p} \cdot p_{s},+\epsilon_{p} \cdot p_{s}\right)$

where $p_{s}^{i}$ is the perturbed model parameter for the $i$-element of the ensemble, $p_{s}$ is the calibrated model parameter and $\epsilon_{p}$ is the fractional parameter error.

\subsubsection{Observation errors}

\subsubsection{Errors related to stage gauge observations}

The errors associated to observations of the $S G$ within the floodplain domain are considered by performing a perturbation of the observed value using a similar approach adopted for perturbing the input flow from stage gauges (Eq. 10). In this case, there is no error due to the rating curve application, considering the water level observations are directly compared to the simulated ones. The water depth for the $i$-element of the ensemble at time $t$ is given by:

$h_{S G, t}^{i}=h_{S G, t}^{\text {true }}+N\left(0, R_{S G}\right)$

250 where $h_{S G, t}^{\text {true }}$ is the observed water level value by the static sensor at time $t, N$ is a noise term normally distributed with zero mean and a given variance $R_{S G}$, assumed equal to $0.02 \mathrm{~m}$ (Schmidt, 2002; Pappenberger et al., 2006).

\subsubsection{Errors related to satellite image observations}

The procedure adopted for deriving water depth distributions from satellite images is affected by a series of errors that must be taken into account and in particular:

- Error in the water surface detection from satellite images this error is due to the water detection technique that could overestimate or underestimate the flood extension. Both multispectral and SAR image processing for water extent mapping require a threshold to apply in respectively the Water Index and the backscatter coefficient. Literature values of these thresholding values could lead to inaccuracies considering optimal threshold values are usually case study or event specific; therefore, a perturbation of the threshold value is performed by adopting a normal distribution with zero mean and a standard deviation derived from literature values (Pierdicca et al., 2009).

- Error of the water surface extraction from the simulated WSE of the hydraulic model. This error is mainly due to the vertical error of the DTM that is used in the water surface elevation interpolation procedure. The generic $i$-DTM of the 
ensemble is perturbed generating a vertical error with a normal distribution characterized by a zero mean and a variance that is uniformly distributed between 0 and $0.3 \mathrm{~m}(U(0,0.3))$ according to literature values (Hodgson and Bresnahan, 2004; Leon et al., 2014; Brouwer et al., 2017). Considering the proposed normally distributed independent errors does not take into account the spatial continuity of the elevation data (Raaflaub and Collins, 2006; Heuvelink et al., 2007), a GIS algorithm for inferring spatially autocorrelated errors is applied. A Correlation Distance $\operatorname{Error}(C D E)$ equal to 100 $\mathrm{m}$ is applied according to Li et al. (2011), Livne and Svoray (2011), Mudron et al. (2013), Leon et al. (2014).

- Error of the water depths derived from the ensemble of hydraulic modelling. Eq 9 assumes a linear relationship between water depth values of two hydraulic profiles and the weight associated to their relative F-indexes expressing the comparison with the observed water extension from $S I$. The application of this weighted mean of the simulated water depths could lead to an inaccuracy on the vertical estimation of the water depths, especially at the boundaries of the two different simulated flood extents. The perturbation error due to the profile derivation for the $i$-element of the ensemble and the generic $k$-cell is expressed as a random uniform noise:

$\operatorname{err}_{P D}^{i, k}=U\left(c \cdot \Delta h_{12}^{k},+c \cdot \Delta h_{12}^{k}\right)$

Where $\Delta h_{12}^{k}$, is the water level difference at the $k$-cell of the two best fitting hydraulic simulations (see Eq. 9); $c$ is a coefficient ranging between 0 and 1, considering that the gentle terrain slopes in floodplains limits the error of water depths derivation in an interval smaller than $\Delta h_{12}^{k}$.

\section{Case study: available data and DA implementation}

\subsection{The Tiber River in central Italy}

The selected case study is represented by the Tiber river upstream of the city of Rome (Figure 3). The fluvial transect goes from the village of Orte Scalo to the northern boundary of the city of Rome corresponding to the Castel Giubileo dam. The entire floodplain domain of the Tiber Orte- Castel Giubileo transect has an extension of $5881 \mathrm{~km}^{2}$, with a main tributary represented by the Nera River (drainage area of $4180 \mathrm{~km}^{2}$ ) and 15 minor ungauged tributaries draining into the selected fluvial domain. The Tiber river at the upstream Orte boundary section has a drainage area of $8400 \mathrm{~km}^{2}$, while at the downstream end of Castel Giubileo the drainage area is $14850 \mathrm{~km}^{2}$ (total Tiber river basin catchment area at the Tyrrhenian sea outlet is approximately $17400 \mathrm{~km}^{2}$ ). The floodplain domain is mostly characterized by agricoltural use, but major road and railway infrastructures were developed connecting several urbanized areas along the Tiber floodplain with four main towns Orte Scalo, Fiano Romano, Monterotondo and the northern part of the city of Rome that have been the subject of frequent floods in January 2014, November 2012, November 2010, and November 2005, causing damages to buildings, roads and bridges. This floodplain domain has also a strategic importance for the flood risk mitigation of the city of Rome considering flood volume accumulation in this domain determine a significant flood peak attenuation that propagates through the historical city center. Understanding, monitoring and predicting flood scenarios in this fluvial domain is crucial for protection the socio-economic and cultural assets of the Italian capital city. The city of Rome EWS strictly relies on the flood modeling predictions of the selected area. 


\subsection{Parametrization of the flood forecasting model}

\subsubsection{Topography and hydrologic modelling}

Topographic data to represent the morphology of the selected Tiber river subbasin domain were gathered from the Tinitaly 10 meter resolution DTM (Tarquini et al., 2012) for supporting the hydrologic modelling. Rainfall time series for rainfallrunoff modeling were gathered from 94 rain gauges with a temporal frequency ranging from 1 to 15 minutes. SCS infiltration method parametrization used 4th level Corine Land Cover dataset gathered from the Istituto Superiore per la Protezione e la Ricerca Ambientale (ISPRA) repositoty, with ancillary data for the lithology and permeability layers gathered from Autorità di Bacino Distrettuale dell'Appennino Centrale. The river basin terrain analysis procedure needed to provide WFIUH hydrologic modelling input parameters used a value of $1 \mathrm{~km}^{2}$ to define stream network source cells, a constant parameter that adequately matched the fluvial network extension observed from aerial images of the basin. WFIUH kinematic parameters were calibrated using 4 small gauged basins (Naja, Niccone, Puglia, Sovara) estimating channel flow velocities equal to $2 \mathrm{~m} / \mathrm{s}$ and distributed hillslope flow velocities in the range 0.01 to $0.1 \mathrm{~m} / \mathrm{s}$.

\subsubsection{D hydraulic modelling}

The bathymetry needed to represent the channel conveyance capacity in the hydraulic model was derived by interpolating available surveyed cross sections. The continuity of the channel-floodplain topographic domain was obtained by using the available high resolution LiDAR DTM (1 meter resolution), gathered from Ministero dell'Ambiente e della Tutela del Territorio e del Mare, that covers most of the selected Tiber river floodplain area. Where LiDAR was not available, the 5 meter resolution DTM from Regione Lazio was used. The floodplain grid cell resolution used for 2D flood unconfined flow routing was set equal to 150 meters to produce computationally efficient model runs. The consistency of the coarse resolution hydraulic model was validated by matching flood simulations with available observations from three recent inundation events (November 2005, November 2010, November 2012). Available flood observations were also used to calibrate the roughness parametrization. A constant Manning coefficient for the channel equal to $0.04 m^{-1 / 3}$ and variable Manning parameters for the floodplain, classified using Corine land cover classes, were calibrated. The 2D hydraulic model validation was performed by comparing simulations with available flood stage time series from seven gauges that were used as floodplain control sections. This also allowed to verify the consistency of the numerical representation of major urban features of the study domain. Flow/stage rating tables available for the main bridges and weirs gathered from the Centro Funzionale regionale del Lazio were used to finalize the 2D hydraulic model validation.

\subsection{DA implementation}

The ensemble size for the application of the EnKF model was defined, according to Anderson (2001), by analyzing the available stage gauges and the selected flood events. The optimal ensemble size was set equal to 40 . 
From the validation of the hydrologic model, the frequency distribution of the relative flow errors was characterized by a mean equal to zero and a standard deviation equal to $0.28 \cdot Q^{\text {true }}$, thus $\alpha_{I}=0.28$ (Eq. 10).

The application of Eq. 11 to consider channel roughness parametrization uncertainties resulted in a $p_{s}=0.04 m^{-1 / 3} / s($ according to the hydraulic model calibration) with $\epsilon_{p}$ assumed equal to 0.125 . This limits the Manning channel value variations between a minimum of 0.035 and a maximum of $0.45 \mathrm{~m}^{-1 / 3} / \mathrm{s}$. The floodplain roughness uncertainty was considered less significant considering that the governing factor for the Tiber floods in the selected domain is the volume, while minor specific urban features and singularities characterized the selected flood events. It is also noted that, for the selected events, the flow is conveyed by the channel for most of the simulation time.

A Landsat 7 image (acquisition date: 14/11/2012 - 09.43) was processed using Eq. 7 to extract the observed flood extension. Landsat 7 products are affected by minor corruptions due to a failure of the satellite Scan Line Corrector (Scaramuzza and Barsi, 2005) that create some data void (i.e. empty stripes) in the water mask. These irregularities were analyzed and interpolated, allowing to overcomes this issue, and define a correct delineation of the flood extension, clearly visible from the available Landsat 7 image. Figure 4 shows the resulting flood detection map. The Landsat 7 image extension covers only a portion of the selected study domain. The satellite image acquisition time is consistent with peak flow conditions within these two gauging stations (Figure 4). A threshold value equal to 0 for MNDWI was chosen (Xu, 2006). To apply the EnKF method, the variance of the random noise related to the threshold value of MNDWI was set equal to 0.2 .

\section{Results and discussion}

Three sets of DA scenarios were selected: 1. stage gauge observations, 2. satellite image observations 3. both SG and SI. Two stage gauges (Ponte Felice and Stimigliano gauging stations) were selected for analyzing water level forecasting performance indexes. However, simultaneous observations from 4 stage gauges were adopted for the application of the hydraulic model updating procedure. The 2005, 2010 and 2012 floods were selected for applying the DA framework using stage gauges observations. The Landsat 7 image, described in Section 3 was assimilated for the 2012 flood event.

\subsection{Assimilation of stage gauge observations}

Figure 5 shows the comparison of observed and simulated water level time series at Ponte Felice station for the 2005, 2010 and 2012 flood events. The first two flood events are characterized by multiple peaks whose rising and recession curves are not properly represented by the open-loop (OL) simulation. This limitation is probably due to the coarse resolution of the flood model. In fact, wetting and drying phenomena along preferential flow pathways are usually influenced by the micro-topography of the domain, that are better represented in higher resolution models (Nicholas and Mitchell, 2003; Neal et al., 2011). The spread of the assimilated ensemble at the stage gauges is very low because of the small error associated to the stage gauge observation as illustrated in Section 2.2.6. The updating of the state variable improves the prediction of the water levels both 
in terms of reduction of the uncertainty (see the red and blue bands of Figure 5) and NSE, R and Bias performance indexes

(Table 1). The performance indexes are calculated considering the stage gauge observations as true values, given their low uncertainty. Bias for both OL and ASS simulations tend to increase above 1 in the downstream stage gauges because of their overestimation of the water levels, especially in the recession limb (that is less important for EWS). For the same reason, for all the simulations, the more the flow is far from to the upstream inflow, the more the $R$ coefficient tends to decay, but in case of ASS simulation, this decay is mitigated.

Figure 6 shows the channel flood profiles for three different time steps (correspondent to three different position of the peak flow along the channel) for the updated (ASS SG) and open-loop (OL) simulations for the November 2012 flood event. It is noted that moving farther from the channel flow observations, the wider is the spread of the ensemble of water levels because of the application of the gain function of Eq. 3 .

Figure 7 shows the impact of water level updating model on the simulated flood extent. In Figure 7 (b) a simulated flood extension subset is shown considering the mean levels of the OL and ASS SG simulations for the November 2012 event. There ASS SG flood extent simulations are on average $7 \mathrm{~km}^{2}$ larger than the OL simulations. Major differences are located in the flat areas where flood extents are very sensitive to flow depth variations. This method can be,thus, accepted in case of a long persistence (e.g. several hours) of water levels at the same location, as in the selected case study. Inaccurate flood extent mapping are, expected for small basins with low flood persistence. The application of this methodology for smaller basins would require an higher flood model and DTM resolution.

\subsection{Assimilation of the satellite observations}

Figure 8 shows the observed and simulated flood hydrographs at Ponte Felice and Stimigliano stations for both the OL and ASS models for the 2012 flood event. The updated mean water levels at the SI acquisition time are slightly higher, and persist to stay higher than the OL simulation for few hours. The spread of the ensemble of the ASS simulation is significantly reduced in correspondence of the SI observation. This reduction is gradually damped until it completely disappears in approximately 8 hours. The improvement of simulation NSE and Bias for the SI assimilation case are not significant (Table 2), considering that the updating persists for only few hours, as shown in Figure 8.

Figure 9 shows the reduction of the water levels uncertainty and the correction of the mean value along the channel profile at the SI acquisition time. It is noted that the proposed SI acquisition approach allows to update the water depths for the entire domain, while the updating with the SG, as shown in Figure 6 does not guarantee a reduction of the uncertainty for the entire domain. The adopted updating procedure allows to increase the flood extent of $4 \mathrm{~km}^{2}$ a the time of the SI acquisition (Figure 10). Despite the smaller water level observation errors given by the stage gauge DA as respect to the SI derived water level uncertainty, the overall change of the mean flood extent between the OL and ASS SI simulations ( $14 \%$ ) does not show significant differences as respect the Stage gauge DA (9\%). 
Figure 11 shows the Bias, Root Mean Square Errors (RMSE) and Standard deviation of the ensembles comparing OL and ASS modelling results after the acquisition of the satellite image at Ponte Felice and Stimigliano stations. Bias is expressed as ratio of the sum of the observed and simulated water levels. Improvements in terms of Bias expressed and RMSE are significant for 20 hours after the SI acquisition, while the uncertainty reduction (i.e. the difference in the ensemble amplitude between the OL and ASS SI simulations) persists for 8 hours.

\subsection{Assimilation of both stage gauge and satellite observations}

400 At the positions where the channel flow gauges are located, it is reasonable to expect that stage gauges observations support better model performances as compared to model updated based on satellite observations. However satellite image observations provide spatially distributed information that are important for flood wave routing in complex domain, especially when flooding impact large unconfined domains. Obtaining multiple stage gauge observations and satellite images constitute the optimal support for DA application for EWSs.

To demonstrate the potential benefit of taking advantages of multiple heterogeneous distributed data sources of flood observations, a failure of the static sensors was simulated, assuming an interruption of the gauge measurements during the flood event (i.e. at 11/11/2012, 09:30). This failure is assumed to happen just before the flood peak occurs. In this way it is tested the value of SI observations in covering the lack of standard SG observations. Figure 12 shows the simulated water level time series at the stage locations comparing the OL simulations as respect the DA of the indirect observations from both stage gauges and the satellite images. Following the simulated failure time, it is noted that the amplitude of the ASS ensemble of water levels become gradually larger until it equals the OL simulation ensemble size. Shortly after the peak flow, the assimilation of the SI determine another narrowing of the amplitude, with small increasing of the mean water levels.

415 A summary of modelling performances is inserted in (Table 3 that show the improvement of the correction in terms of NSE and Bias indices. The combined assimilation of the two observation sources determined an overall improvement as respect to the case where only SI data are available (Table 2). This demonstrated the potential benefit of assimilating simultaneously different observations. Bias, RMSE and variance of the ensemble amplitude as a function of lead time are represented in Figure 13. Overall simulation Bias and RMSE improve following the assimilation of the SG, but not after the updating due to the SI. However, Bias and RMSE improved locally if calculated starting from the acquisition of the SI as showed in Figure 11 . On the other hand, the variance of the amplitude of the ensemble show an improvement of the updated model in terms of reduction of uncertainty right after the assimilation of the SI. 


\subsection{Pros and challenges}

The adopted hydraulic model has a coarse spatial resolution ( $150 \mathrm{~m}$ cell size) and its performance can be considered acceptable for high magnitude flood events; however some limitations could raise in representing the flow patterns for low magnitude events, where micro topography can have an important role in the flow propagation (Bates 2012). Further tests considering smaller domain with a higher resolution 2D hydraulic model are needed to verify the stability of the model updating, when water levels corrections are applied to cells characterized with smaller dimensions. Moreover, the model uncertainty can be considered quite large during the peak flows of the selected flood events with an amplitude of the ensemble of the water levels even equal to 2 meters (see Figures 8 and 9). More accurate models could not benefit from the assimilation of the satellite image, if the indirect water level distribution derivation is affected by uncertainties larger than the one ones related to the forecasting model. Tables 1, 2 and 3 shows also some bias in the hydraulic model, mostly prominent in the recession limb of the hydrographs. This is a limitation, since the optimality of the DA techniques is realized if the observations and the models are not biased (Dee, 2005; Liu et al., 2012).Bias reductions and further improvement of the simulation can be done by updating the model parameters (e.g. the roughness) using an augmented state vector approach in the EnKF framework (Montzka et al., 2012).

The simplified rainfall-runoff modelling allowed to generate input flow hydrographs very quickly according to the needs of a near-real time flood modelling purpose. However, the model can be considered appropriate only for small basins characterized by an impulsive response, for which the groundwater component can be neglected, complex topography and flow control structures are absent to avoid equifinality issues during the calibration/validation analysis (Beven, 2006). Furthermore the application of the SCS-CN model at sub-daily time scale (Grimaldi et al., 2013) is a strong limitation and more advanced models should be preferred for reduce the model uncertainties.

Despite the several measures adopted to prevent instability issues, instability can occur during the updating of the water levels from the stage gauges. For this reason, the model is tailored to remove from the ensemble the critical elements casing instability and generate new elements in order to keep the sample size constant. This measure can slow down the model, that should be as fast as possible for a proper near-real time application. The instability issues that sometimes can occur could be due to the fact that FLO-2D model doesn't allow to update the flow velocities but only the flow depths. This limitation doesn't also enable to have control of the volume conservation, that is an important factor to verify the accuracy of the model simulation.

A methodology for indirectly deriving the distribution of the water depths from the water footprint gathered from a satellite image was proposed; this methodology is affected by a series of errors that were taken in to account for assigning a proper reliability to the observation related to the satellite image; this reliability is numerically lower than the one related to stage gauges observations, but at the same time, provides distributed information instead of the local ones given by the static sensors. The derivation of the water depths from the flood extent gathered by the satellite image was performed with a linear combination of the values given by the ensemble of the results provided by the hydraulic forecasting model. Since the latter has to be updated by an observation that is indirectly derived by the model itself, this approach can be considered disputable; however, practically it demonstrated to not cause instability issues during the model updating, since the distribution of the flow depths 
is coherent with the model state variable and it has demonstrated to slightly improve the model performance. This approach can be considered as an hybrid methodology of two literature approaches that consider prognostic and diagnostic variables for assimilating satellite derived information (Hostache et al., 2018), taking advantage of the rapid flood detection algorithms adopted for direct assimilating the flood extent and, at the same time, directly retrieving the water levels that are prognostic variables, thus more straightforward to assimilate than the flood extent (Hostache et al., 2018).

During a flood event, the adoption, as observation, of a multispectral image, potentially corruptible by the cloud covering and sunlight is much less likely than the one with a SAR image; however, the proposed approach for the model updating can be applicable regardless the type of image as input observation. The satellite revisit time of the current satellite missions is still a strong limitation, since can be much higher than the travel time of small basins. Furthermore, usually multispectral SAR images require time for being processed. However, new satellite missions and also the combination of more constellations will considerably reduce the revisit time in the near future, allowing to have different images for the same area with a temporal frequency higher than the persistence of the model correction ( 8 hours). Moreover, recent automatic satellite image techniques for extracting the flood extension have been implemented in real time services for flood mapping (Martinis et al. 2015).

\section{Conclusive remarks and future work}

The proposed DA framework investigated on the opportunities and challenges of assimilating multiple sources of observations for improving the performances of near real time flood predictions. Specifically, stage gauge water level readings and satellite-derived flood extents were used for testing the proposed DA framework. A real flood event, selected as case study, showed that the assimilation of stage gauges significantly improved the flood model performances in terms of NSE, R Bias, also reducing simulated inundation extent uncertainties. The assimilation of distributed flood depths, indirectly retrieved from satellite-derived flood extent, provided slightly better modelling performances. Therefore, future tests are needed, taking advantage of increasing availability of satellite-derived flood extents at higher temporal and spatial resolution, to discover the effective capacity of the proposed flexible multi-source DA framework to value a larger EO data availability.

Moreover, the flexibility of the proposed model, to assimilate local and distributed observations, suggests its suitability to use other data sources, also gathered from informal observation systems. In particular, future work will allow to investigate on the use of crowd-sourced observations to apply the proposed flood prediction framework in ungauged basins. Crowdsourcing already proved to be an effective means to improve hydrologic (Mazzoleni et al. 2017) and hydraulic (Annis and Nardi 2019) modelling performances, but further work is needed to test the use of crowdsourced data in real time flood modelling approaches. Significant improvements are expected in the near future for improved weather predictions by valuing all data sources, especially affordable citizen-driven observations for developing countries that are the most vulnerable to hydro-extremes (Alley et al. 2019). 
https://doi.org/10.5194/hess-2021-125

Preprint. Discussion started: 8 April 2021

(c) Author(s) 2021. CC BY 4.0 License.

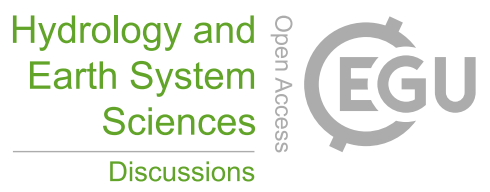

(c) (1)

Discussions

Acknowledgements. FN and AA acknowledge the support received by the WARREDOC center of University for Foreigners of Perugia through the WARREDOC-Fondazione ENI Enrico Mattei (FEEM) research agreement. FN acknowledges the support received by the Southeast Environmental Research Center in the Institute of Environment at Florida International University. 


\section{References}

Alley, R. B., Emanuel, K. A., and Zhang, F.: Advances in weather prediction, Science, 363, 342-344, 2019.

Anderson, J. L.: An ensemble adjustment Kalman filter for data assimilation, Monthly weather review, 129, $2884-2903,2001$.

Andreadis, K. M. and Schumann, G. J.: Estimating the impact of satellite observations on the predictability of large-scale hydraulic models, Advances in water resources, 73, 44-54, 2014.

Andreadis, K. M., Clark, E. A., Lettenmaier, D. P., and Alsdorf, D. E.: Prospects for river discharge and depth estimation through assimilation of swath-altimetry into a raster-based hydrodynamics model, Geophysical Research Letters, 34, 1-5, 2007.

Annis, A. and Nardi, F.: Integrating VGI and 2D hydraulic models into a data assimilation framework for real time flood forecasting and mapping, Geo-spatial Information Science, 22, 223-236, 2019.

Annis, A., Nardi, F., Morrison, R., and Castelli, F.: Investigating hydrogeomorphic floodplain mapping performance with varying DTM resolution and stream order, Hydrological Sciences Journal, 64, 525-538, 2019.

Baldassarre, G. D. and Montanari, A.: Uncertainty in river discharge observations: a quantitative analysis, Hydrology and Earth System Sciences, 13, 913-921, 2009.

Bates, P. D.: Integrating remote sensing data with flood inundation models: how far have we got?, Hydrological Processes, 26, 2515-2521, 2012.

Beven, K.: A manifesto for the equifinality thesis, Journal of hydrology, 320, 18-36, 2006.

Biancamaria, S., Durand, M., Andreadis, K., Bates, P., Boone, A., Mognard, N., Rodriguez, E., Alsdorf, D., Lettenmaier, D., and Clark, E.: Assimilation of virtual wide swath altimetry to improve Arctic river modeling, Remote Sensing of Environment, 115, 373-381, 2011.

Brivio, P., Colombo, R., Maggi, M., and Tomasoni, R.: Integration of remote sensing data and GIS for accurate mapping of flooded areas, International Journal of Remote Sensing, 23, 429-441, 2002.

Brouwer, T., Eilander, D., Van Loenen, A., Booij, M. J., Wijnberg, K. M., Verkade, J. S., and Wagemaker, J.: Probabilistic flood extent estimates from social media flood observations., Natural Hazards \& Earth System Sciences, 17, 735-747, 2017.

Clark, M. P., Rupp, D. E., Woods, R. A., Zheng, X., Ibbitt, R. P., Slater, A. G., Schmidt, J., and Uddstrom, M. J.: Hydrological data assimilation with the ensemble Kalman filter: Use of streamflow observations to update states in a distributed hydrological model, Advances in water resources, 31, 1309-1324, 2008.

Cloke, H. and Pappenberger, F.: Ensemble flood forecasting: A review, Journal of hydrology, 375, 613-626, 2009.

Cronshey, R.: Urban hydrology for small watersheds, Tech. rep., US Dept. of Agriculture, Soil Conservation Service, Engineering Division, 1986.

Dee, D. P.: Bias and data assimilation, Quarterly Journal of the Royal Meteorological Society, 131, 3323-3343, 2005.

Demeritt, D., Cloke, H., Pappenberger, F., Thielen, J., Bartholmes, J., and Ramos, M.-H.: Ensemble predictions and perceptions of risk, uncertainty, and error in flood forecasting, Environmental Hazards, 7, 115-127, 2007.

Desai, B., Maskrey, A., Peduzzi, P., De Bono, A., and Herold, C.: Making development sustainable: the future of disaster risk management, global assessment report on disaster risk reduction, 2015.

EM-DAT, C.: The OFDA/CRED International Disaster Database. Universite Catholique de Louvain, Brussels, Belgium, 2016.

Evensen, G.: The ensemble Kalman filter: Theoretical formulation and practical implementation, Ocean dynamics, 53, 343-367, 2003.

García-Pintado, J., Neal, J. C., Mason, D. C., Dance, S. L., and Bates, P. D.: Scheduling satellite-based SAR acquisition for sequential assimilation of water level observations into flood modelling, Journal of Hydrology, 495, 252-266, 2013. 
Giustarini, L., Matgen, P., Hostache, R., Montanari, M., Guingla, P., Antonio, D., Pauwels, V., De Lannoy, G., De Keyser, R., Pfister, L., et al.: Assimilating SAR-derived water level data into a hydraulic model: a case study, Hydrology and Earth System Sciences, 15, 2349-2365, 2011.

Grimaldi, S., Petroselli, A., and Nardi, F.: A parsimonious geomorphological unit hydrograph for rainfall-runoff modelling in small ungauged basins, Hydrological Sciences Journal, 57, 73-83, 2012.

Grimaldi, S., Petroselli, A., and Romano, N.: Green-Ampt Curve-Number mixed procedure as an empirical tool for rainfall-runoff modelling in small and ungauged basins, Hydrological processes, 27, 1253-1264, 2013.

Grimaldi, S., Li, Y., Pauwels, V. R., and Walker, J. P.: Remote sensing-derived water extent and level to constrain hydraulic flood forecasting models: Opportunities and challenges, Surveys in Geophysics, 37, 977-1034, 2016.

Haan, C. T., Barfield, B. J., and Hayes, J. C.: Design hydrology and sedimentology for small catchments, Elsevier, 1994.

Heuvelink, G. B., Brown, J. D., and van Loon, E. E.: A probabilistic framework for representing and simulating uncertain environmental variables, International Journal of Geographical Information Science, 21, 497-513, 2007.

Hodgson, M. E. and Bresnahan, P.: Accuracy of airborne LiDAR-derived elevation, Photogrammetric Engineering \& Remote Sensing, 70, 331-339, 2004.

Horritt, M. and Bates, P.: Predicting floodplain inundation: raster-based modelling versus the finite-element approach, Hydrological processes, 15, 825-842, 2001

Hostache, R., Lai, X., Monnier, J., and Puech, C.: Assimilation of spatially distributed water levels into a shallow-water flood model. Part II: Use of a remote sensing image of Mosel River, Journal of hydrology, 390, 257-268, 2010.

Hostache, R., Matgen, P., Montanari, A., Montanari, M., Hoffmann, L., and Pfister, L.: Propagation of uncertainties in coupled hydrometeorological forecasting systems: A stochastic approach for the assessment of the total predictive uncertainty, Atmospheric research, 100, 263-274, 2011.

Hostache, R., Chini, M., Giustarini, L., Neal, J., Kavetski, D., Wood, M., Corato, G., Pelich, R.-M., and Matgen, P.: Near-Real-Time Assimilation of SAR-Derived Flood Maps for Improving Flood Forecasts, Water Resources Research, 54, 5516-5535, 2018.

Jenson, S. K. and Domingue, J. O.: Extracting topographic structure from digital elevation data for geographic information system analysis, Photogrammetric engineering and remote sensing, 54, 1593-1600, 1988.

Knight, D. and Shamseldin, A.: River basin modelling for flood risk mitigation, CRC Press, 2005.

Krzhizhanovskaya, V. V., Shirshov, G., Melnikova, N., Belleman, R. G., Rusadi, F., Broekhuijsen, B., Gouldby, B., Lhomme, J., Balis, B., Bubak, M., et al.: Flood early warning system: design, implementation and computational modules, Procedia Computer Science, 4 , 106-115, 2011.

Kundzewicz, Z. W.: 15 Floods: lessons about early warning systems, Late lessons from early warnings: science, precaution, innovation, p. 25, 2013.

Lai, X., Liang, Q., Yesou, H., and Daillet, S.: Variational assimilation of remotely sensed flood extents using a 2-D flood model, Hydrology and Earth System Sciences, 18, 4325-4339, 2014.

Leon, J. X., Heuvelink, G. B., and Phinn, S. R.: Incorporating DEM uncertainty in coastal inundation mapping, PLoS one, 9, e108 727, 2014. Li, S., MacMillan, R., Lobb, D. A., McConkey, B. G., Moulin, A., and Fraser, W. R.: Lidar DEM error analyses and topographic depression identification in a hummocky landscape in the prairie region of Canada, Geomorphology, 129, 263-275, 2011.

Liu, Y. and Gupta, H. V.: Uncertainty in hydrologic modeling: Toward an integrated data assimilation framework, Water Resources Research, 43, 1-18, 2007. 
Liu, Y., Weerts, A., Clark, M., Hendricks Franssen, H.-J., Kumar, S., Moradkhani, H., Seo, D.-J., Schwanenberg, D., Smith, P., Van Dijk, A., et al.: Advancing data assimilation in operational hydrologic forecasting: progresses, challenges, and emerging opportunities, Hydrol. Earth Syst. Sci., 16, 3863-3887, 2012.

Livne, E. and Svoray, T.: Components of uncertainty in primary production model: the study of DEM, classification and location error,

Madsen, H. and Skotner, C.: Adaptive state updating in real-time river flow forecasting-A combined filtering and error forecasting procedure, Journal of Hydrology, 308, 302-312, 2005.

Martinis, S., Kersten, J., and Twele, A.: A fully automated TerraSAR-X based flood service, ISPRS Journal of Photogrammetry and Remote Sensing, 104, 203-212, 2015.

Mason, D., Schumann, G.-P., Neal, J., Garcia-Pintado, J., and Bates, P.: Automatic near real-time selection of flood water levels from high resolution Synthetic Aperture Radar images for assimilation into hydraulic models: a case study, Remote Sensing of Environment, 124, 705-716, 2012

Matgen, P., Schumann, G., Pappenberger, F., and Pfisterz, L.: Sequential assimilation of remotely sensed water stages in flood inundation models, IAHS PUBLICATION, 316, 78, 2007.

580 Matgen, P., Montanari, M., Hostache, R., Pfister, L., Hoffmann, L., Plaza, D., Pauwels, V., De Lannoy, G., De Keyser, R., and Savenije, H.: Towards the sequential assimilation of SAR-derived water stages into hydraulic models using the Particle Filter: proof of concept, Hydrology and Earth System Sciences, 14, 1773-1785, 2010.

Mazzoleni, M., Verlaan, M., Alfonso, L., Monego, M., Norbiato, D., Ferri, M., and Solomatine, D. P.: Can assimilation of crowdsourced data in hydrological modelling improve flood prediction?, Hydrology \& Earth System Sciences, 21, 839-861, 2017.

McCuen, R. H.: Uncertainty analyses of watershed time parameters, Journal of Hydrologic Engineering, 14, 490-498, 2009.

McLaughlin, D.: An integrated approach to hydrologic data assimilation: interpolation, smoothing, and filtering, Advances in Water Resources, 25, 1275-1286, 2002.

McMillan, H., Hreinsson, E., Clark, M., Singh, S., Zammit, C., and Uddstrom, M.: Operational hydrological data assimilation with the recursive ensemble Kalman filter, Hydrology and Earth System Sciences, 17, 21-38, 2013.

590 Mesa, O. J. and Mifflin, E. R.: On the relative role of hillslope and network geometry in hydrologic response, in: Scale problems in hydrology, pp. 1-17, Springer, 1986.

Montzka, C., Pauwels, V., Franssen, H.-J., Han, X., and Vereecken, H.: Multivariate and multiscale data assimilation in terrestrial systems: A review, Sensors, 12, 16291-16333, 2012.

Moradkhani, H., Hsu, K.-L., Gupta, H., and Sorooshian, S.: Uncertainty assessment of hydrologic model states and parameters: Sequential data assimilation using the particle filter, Water resources research, 41, 1-17, 2005.

Mudron, I., Podhoranyi, M., Cirbus, J., Devečka, B., and Bakay, L.: Modelling the Uncertainty of Slope Estimation from a Lidar-Derived Dem: a Case Study from a Large-Scale Area in the Czech Republic/Modelovanie Neistoty Vo Vỳpočte Sklonov Z Lidarovỳch Dmr; Prípadová Štúdia Vybraného Malého Územia V Čr, GeoScience Engineering, 59, 25-39, 2013.

Murphy, J.: The impact of ensemble forecasts on predictability, Quarterly Journal of the Royal Meteorological Society, 114, 463-493, 1988.

600 Nardi, F., Vivoni, E. R., and Grimaldi, S.: Investigating a floodplain scaling relation using a hydrogeomorphic delineation method, Water Resources Research, 42, 1-15, 2006. 
Nardi, F., Biscarini, C., Di Francesco, S., Manciola, P., and Ubertini, L.: Comparing a large-scale dem-based floodplain delineation algorithm with standard flood maps: The tiber river basin case study, Irrigation and Drainage, 62, 11-19, https://doi.org/10.1002/ird.1818, cited By $29,2013$.

Nardi, F., Morrison, R. R., Annis, A., and Grantham, T. E.: Hydrologic scaling for hydrogeomorphic floodplain mapping: Insights into human-induced floodplain disconnectivity, River Research and Applications, 34, 675-685, 2018.

Neal, J., Schumann, G., Bates, P., Buytaert, W., Matgen, P., and Pappenberger, F.: A data assimilation approach to discharge estimation from space, Hydrological Processes: An International Journal, 23, 3641-3649, 2009.

Neal, J., Schumann, G., Fewtrell, T., Budimir, M., Bates, P., and Mason, D.: Evaluating a new LISFLOOD-FP formulation with data from the summer 2007 floods in Tewkesbury, UK, Journal of Flood Risk Management, 4, 88-95, 2011.

Neal, J. C., Atkinson, P. M., and Hutton, C. W.: Flood inundation model updating using an ensemble Kalman filter and spatially distributed measurements, Journal of hydrology, 336, 401-415, 2007.

Nicholas, A. and Mitchell, C.: Numerical simulation of overbank processes in topographically complex floodplain environments, Hydrological Processes, 17, 727-746, 2003

NRCS: Ponds-Planning, design, construction., Washington, DC: US Natural Resources Conservation Service Agriculture Handbook no. 590, 1997.

O’brien, J., Julien, P., and Fullerton, W.: Two-dimensional water flood and mudflow simulation, Journal of hydraulic engineering, 119 , 244-261, 1993.

Pappenberger, F., Matgen, P., Beven, K. J., Henry, J.-B., Pfister, L., et al.: Influence of uncertain boundary conditions and model structure on flood inundation predictions, Advances in Water Resources, 29, 1430-1449, 2006.

Pierdicca, N., Chini, M., Pulvirenti, L., Candela, L., Ferrazzoli, P., Guerriero, L., Boni, G., Siccardi, F., and Castelli, F.: Using COSMOSkyMed data for flood mapping: Some case-studies, in: 2009 IEEE International Geoscience and Remote Sensing Symposium, vol. 2, pp. II-933, IEEE, 2009.

Raaflaub, L. D. and Collins, M. J.: The effect of error in gridded digital elevation models on the estimation of topographic parameters, Environmental Modelling \& Software, 21, 710-732, 2006.

Rakovec, O., Weerts, A., Hazenberg, P., Torfs, P., and Uijlenhoet, R.: State updating of a distributed hydrological model with Ensemble Kalman Filtering: effects of updating frequency and observation network density on forecast accuracy, Hydrology and Earth System Sciences, 16, 3435-3449, 2012.

Reichle, R. H., McLaughlin, D. B., and Entekhabi, D.: Hydrologic data assimilation with the ensemble Kalman filter, Monthly Weather Review, 130, 103-114, 2002.

Revilla-Romero, B., Wanders, N., Burek, P., Salamon, P., and de Roo, A.: Integrating remotely sensed surface water extent into continental scale hydrology, Journal of hydrology, 543, 659-670, 2016.

Rodriguez-Iturbe, I. and Rinaldo, A.: Fractal river networks: chance and self-organization, 1997.

Scaramuzza, P. and Barsi, J.: Landsat 7 scan line corrector-off gap-filled product development, in: Proceeding of Pecora, vol. 16, pp. 23-27, 2005.

Schmidt, A. R.: Analysis of stage-discharge relations for open-channel flows and their associated uncertainties, Ph.D. thesis, University of Illinois at Urbana-Champaign, 2002.

Tarboton, D. G., Bras, R. L., and Rodriguez-Iturbe, I.: On the extraction of channel networks from digital elevation data, Hydrological processes, 5, 81-100, 1991 . 
https://doi.org/10.5194/hess-2021-125

Preprint. Discussion started: 8 April 2021

(c) Author(s) 2021. CC BY 4.0 License.

640 Tarquini, S., Vinci, S., Favalli, M., Doumaz, F., Fornaciai, A., and Nannipieri, L.: Release of a 10-m-resolution DEM for the Italian territory: Comparison with global-coverage DEMs and anaglyph-mode exploration via the web, Computers \& geosciences, 38, 168-170, 2012.

Thampapillai, D. J. and Musgrave, W. F.: Flood damage mitigation: A review of structural and nonstructural measures and alternative decision frameworks, Water Resources Research, 21, 411-424, 1985.

Thiessen, A. H.: Precipitation averages for large areas, Monthly weather review, 39, 1082-1089, 1911.

645 Weerts, A. H. and El Serafy, G. Y.: Particle filtering and ensemble Kalman filtering for state updating with hydrological conceptual rainfallrunoff models, Water resources research, 42, 1-17, 2006.

Wing, O. E., Quinn, N., Bates, P. D., Neal, J. C., Smith, A. M., Sampson, C. C., Coxon, G., Yamazaki, D., Sutanudjaja, E. H., and Alfieri, L.: Toward Global Stochastic River Flood Modeling, Water Resources Research, 56, e2020WR027 692, 2020.

Wood, M., Hostache, R., Neal, J., Wagener, T., Giustarini, L., Chini, M., Corato, G., Matgen, P., and Bates, P.: Calibration of channel depth and friction parameters in the LISFLOOD-FP hydraulic model using medium-resolution SAR data and identifiability techniques, Hydrology and Earth System Sciences, 20, 4983-4997, 2016.

$\mathrm{Xu}, \mathrm{H}$.: Modification of normalised difference water index (NDWI) to enhance open water features in remotely sensed imagery, International journal of remote sensing, 27, 3025-3033, 2006. 


\section{TABLES}

\begin{tabular}{llcccccc}
\hline \multirow{2}{*}{ Event } & \multirow{2}{*}{ Station } & \multicolumn{2}{c}{ NSE } & \multicolumn{2}{c}{ R } & \multicolumn{2}{c}{ BIAS } \\
& & OL & ASS. & OL & ASS. & OL & ASS. \\
\hline \multirow{2}{*}{ Nov. 2005 } & Ponte Felice & 0.890 & 0.982 & 0.977 & 0.993 & 1.040 & 0.998 \\
& Stimigliano & 0.600 & 0.932 & 0.949 & 0.967 & 0.983 & 0.999 \\
& Nazzano & 0.736 & 0.948 & 0.941 & 0.982 & 1.028 & 1.009 \\
& Ponte del Grillo & 0.614 & 0.886 & 0.891 & 0.959 & 1.043 & 1.027 \\
\hline \multirow{3}{*}{ Nov. 2010 } & Ponte Felice & 0.843 & 0.977 & 0.983 & 0.989 & 1.079 & 0.998 \\
& Stimigliano & 0.633 & 0.944 & 0.945 & 0.976 & 0.973 & 0.996 \\
& Nazzano & 0.688 & 0.976 & 0.969 & 0.990 & 1.053 & 1.006 \\
& Ponte del Grillo & 0.414 & 0.954 & 0.937 & 0.979 & 1.148 & 1.008 \\
\hline \multirow{2}{*}{ Nov. 2012 } & Ponte Felice & 0.904 & 0.972 & 0.971 & 0.987 & 1.013 & 0.988 \\
& Stimigliano & 0.808 & 0.942 & 0.958 & 0.971 & 0.952 & 0.996 \\
& Nazzano & 0.672 & 0.967 & 0.857 & 0.983 & 1.028 & 1.000 \\
& Ponte del Grillo & 0.637 & 0.916 & 0.824 & 0.961 & 1.061 & 1.028 \\
\hline
\end{tabular}

Table 1. NSE, R and Bias for open-loop and stage gauge data assimilation simulations at Ponte Felice, Stimigliano. Nazzano, Ponte del Grillo stations for the 2005, 2010 and 2012 flood events

\begin{tabular}{lcccccc}
\hline \multirow{2}{*}{ Station } & \multicolumn{2}{c}{ NSE } & \multicolumn{2}{c}{ R } & \multicolumn{2}{c}{ BIAS } \\
& OL & ASS. & OL & ASS. & OL & ASS. \\
\hline Ponte Felice & 0.904 & 0.905 & 0.971 & 0.970 & 1.010 & 1.011 \\
Stimigliano & 0.759 & 0.765 & 0.950 & 0.949 & 0.951 & 0.951 \\
Nazzano & 0.687 & 0.695 & 0.900 & 0.899 & 1.026 & 1.027 \\
Ponte del Grillo & 0.645 & 0.651 & 0.825 & 0.823 & 1.058 & 1.060 \\
\hline
\end{tabular}

Table 2. NSE, R and Bias for open-loop and SI assimilation simulations at Ponte Felice, Stimigliano. Nazzano, Ponte del Grillo station for the $\mathrm{d} 2012$ flood event. 
https://doi.org/10.5194/hess-2021-125

Preprint. Discussion started: 8 April 2021

(c) Author(s) 2021. CC BY 4.0 License.

\begin{tabular}{lcccccc}
\hline \multirow{2}{*}{ Station } & \multicolumn{2}{c}{ NSE } & \multicolumn{2}{c}{ R } & \multicolumn{2}{c}{ BIAS } \\
& OL & ASS. & OL & ASS. & OL & ASS. \\
\hline Ponte Felice & 0.904 & 0.950 & 0.971 & 0.986 & 1.008 & 0.965 \\
Stimigliano & 0.792 & 0.810 & 0.958 & 0.945 & 0.948 & 0.959 \\
Nazzano & 0.682 & 0.694 & 0.860 & 0.844 & 1.024 & 1.015 \\
Ponte del Grillo & 0.651 & 0.657 & 0.828 & 0.822 & 1.054 & 1.043 \\
\hline
\end{tabular}

Table 3. NSE, R and Bias for open-loop and both SG and SI assimilation simulations at Ponte Felice, Stimigliano. Nazzano, Ponte del Grillo station for the $\mathrm{d} 2012$ flood event. 
https://doi.org/10.5194/hess-2021-125

Preprint. Discussion started: 8 April 2021

(c) Author(s) 2021. CC BY 4.0 License.

Hydrology and
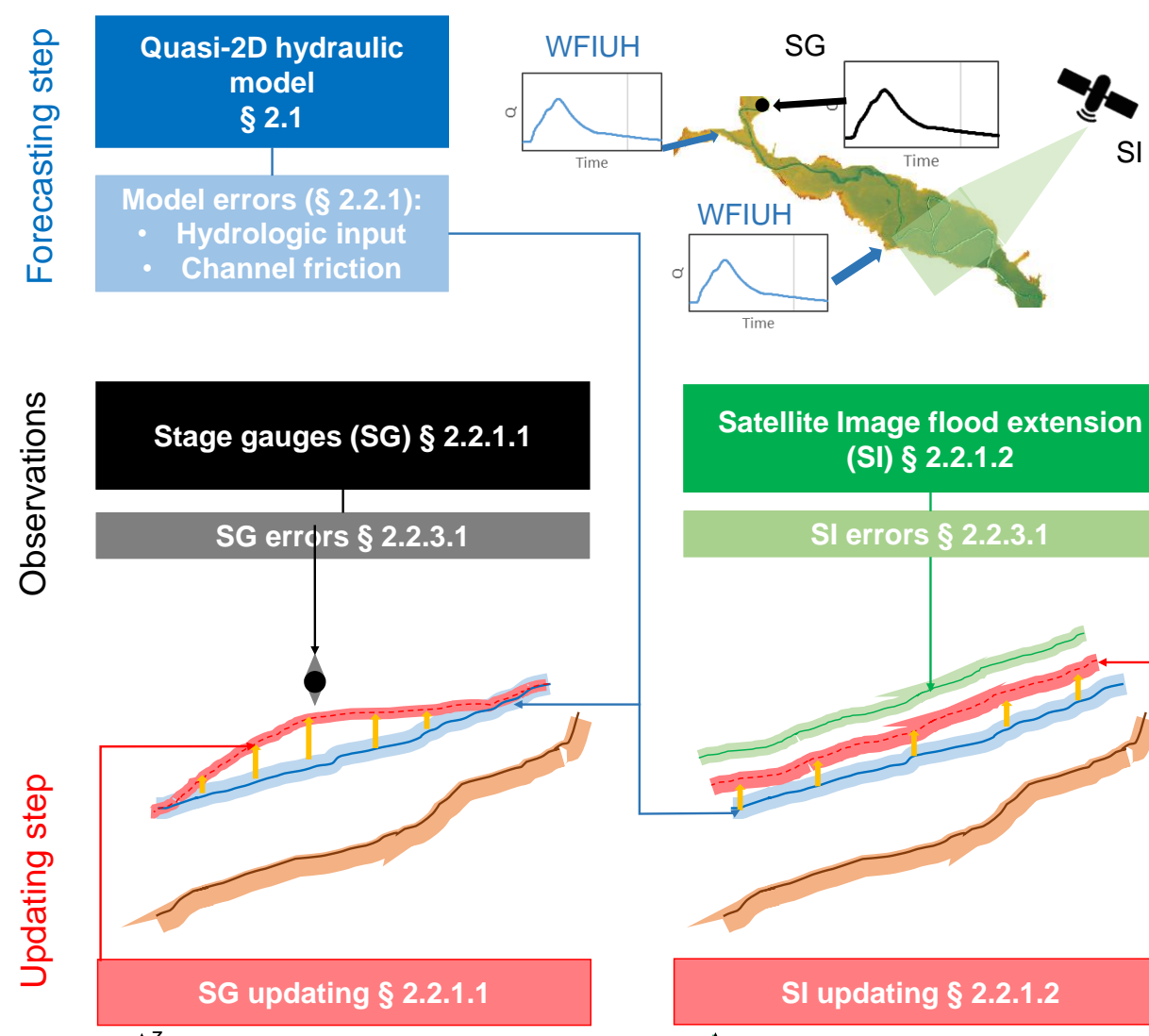

\section{Satellite Image flood extension \\ (SI) § 2.2.1.2}
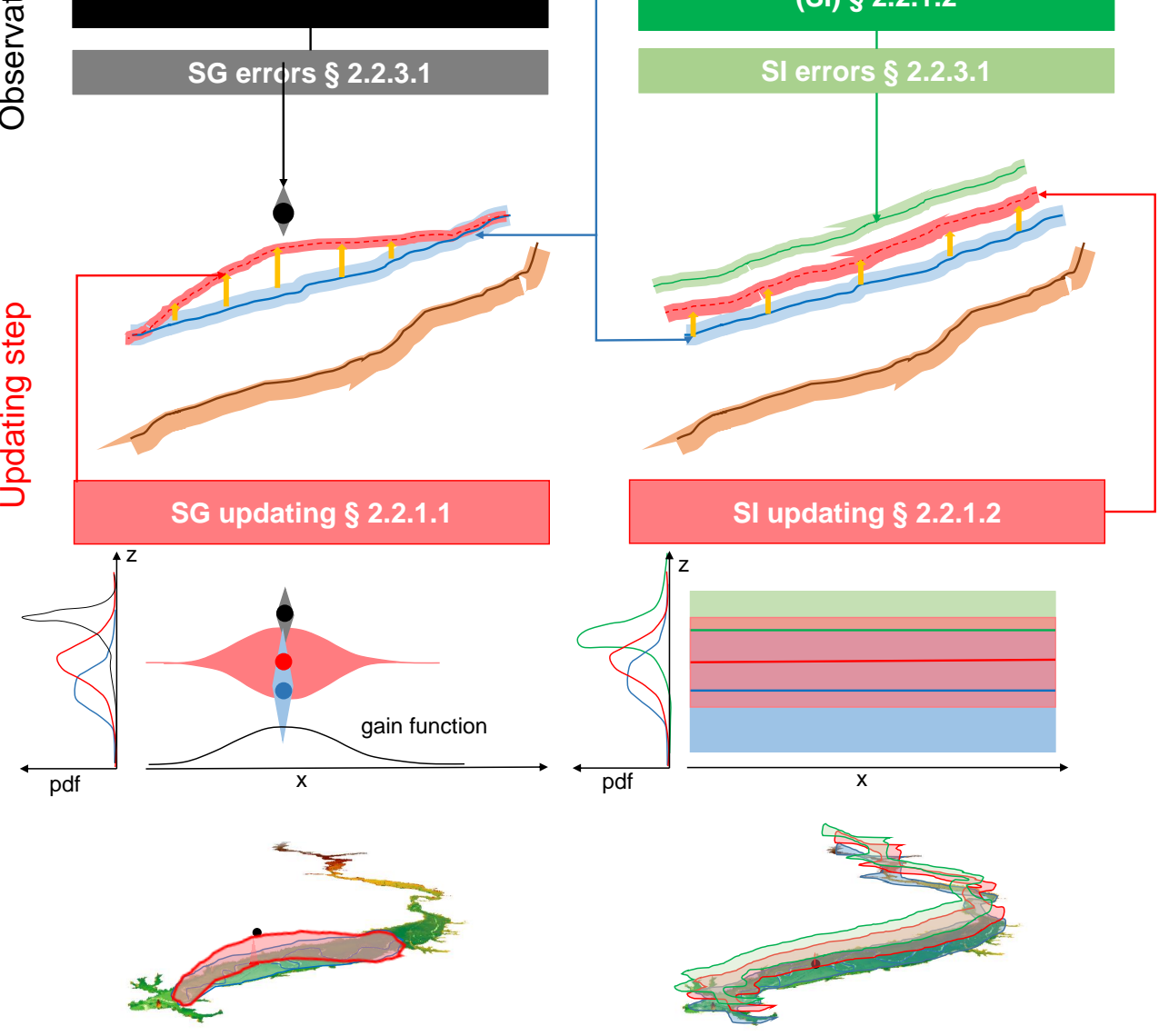

Figure 1. Scheme of the Data Assimilation(DA) framework 
https://doi.org/10.5194/hess-2021-125

Preprint. Discussion started: 8 April 2021

(c) Author(s) 2021. CC BY 4.0 License.
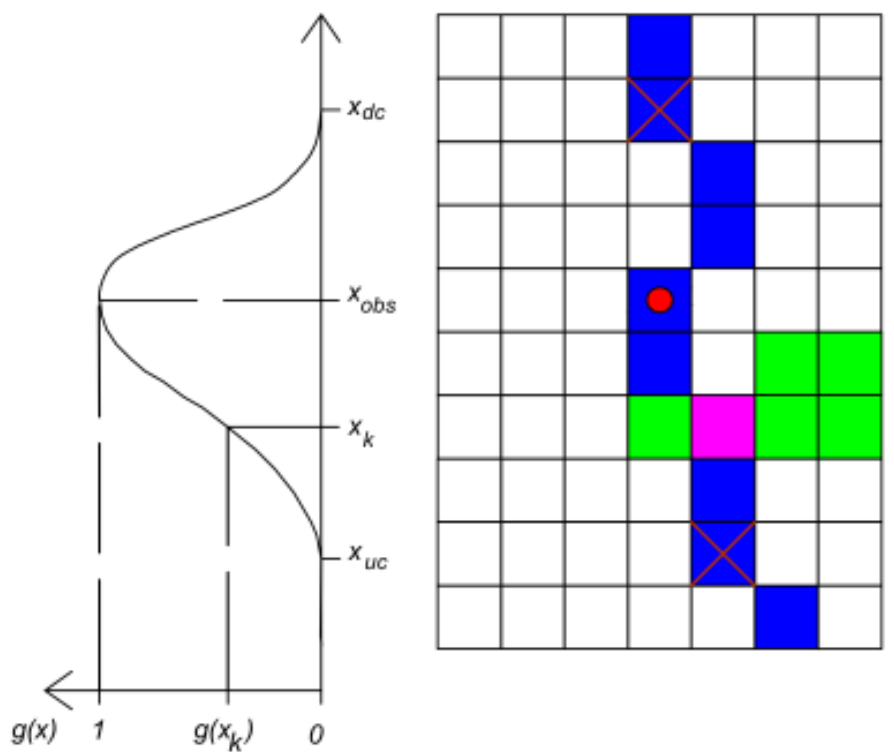

Floodplain cells

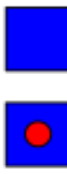

Channel cells

Stage gage cell

Bounding cells

k-cell

Floodplain cells nearest to k-cell

Figure 2. Scheme of the cells updating in the channel and floodplain domain adopting a gain function assimilating the stage gauges measurements 


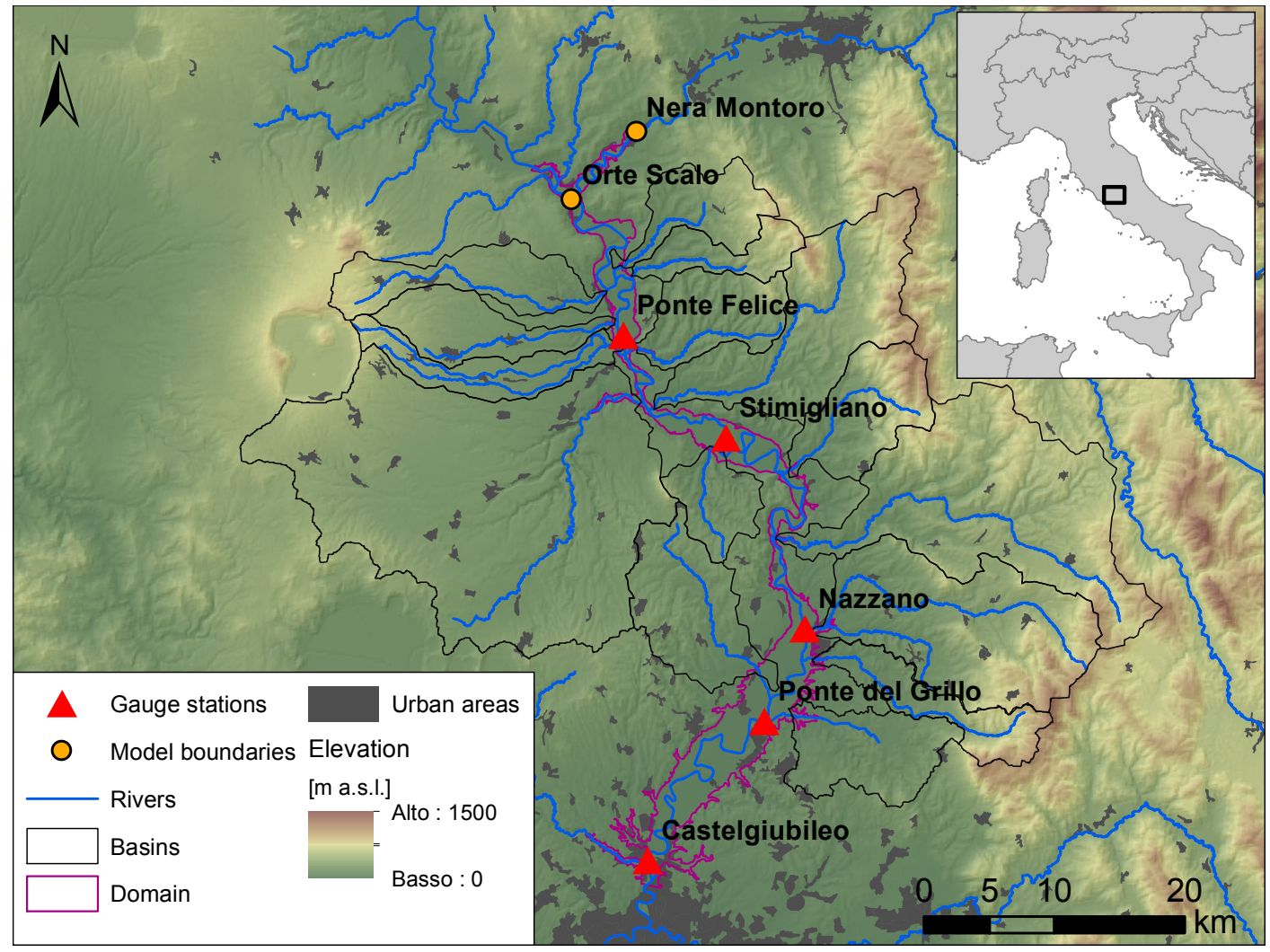

Figure 3. Map of the study basin with the contributing lateral river basins, the model boundaries and the reference gauge stations 


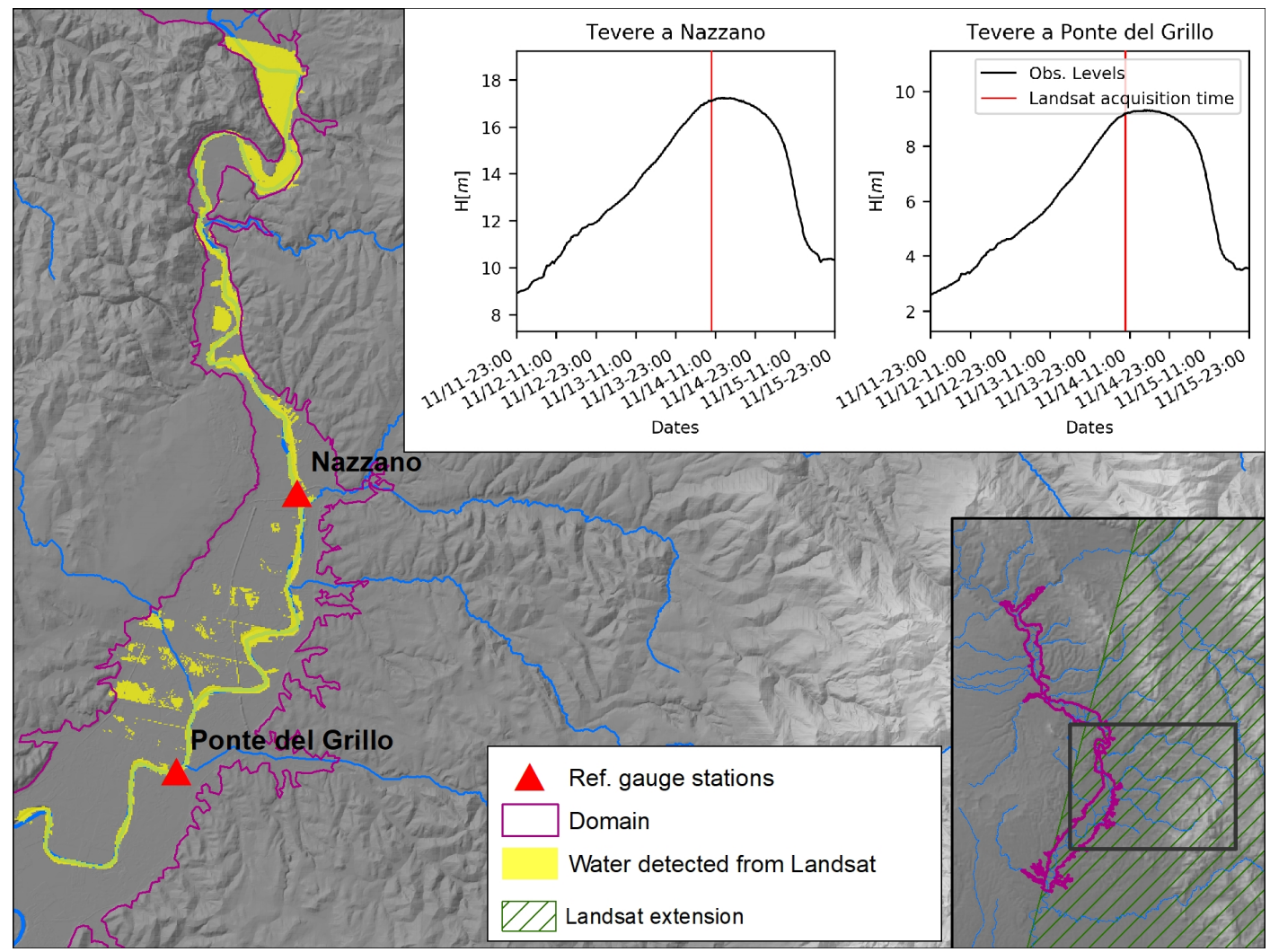

Figure 4. Extension of the water detected from the Landsat 7 image (acquisition date: 14/11/2012 - 09.43) in the computational hydraulic domain with the position of the Landsat acquisition time compared to the time series of the water depths in Nazzano and Ponte del Grillo gauge stations 
https://doi.org/10.5194/hess-2021-125

Preprint. Discussion started: 8 April 2021

(c) Author(s) 2021. CC BY 4.0 License.

(c) (i)
Hydrology and Earth System Sciences Discussions
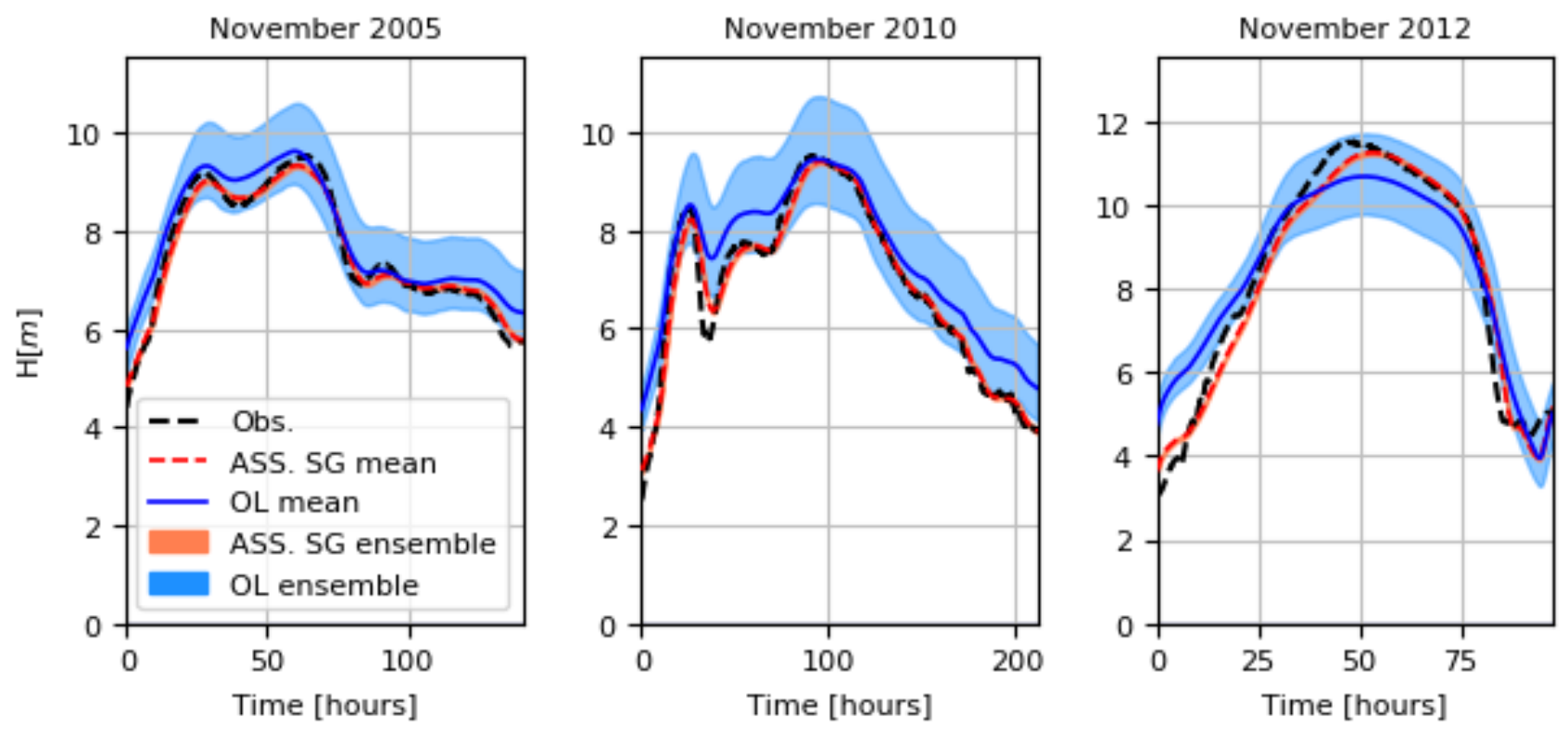

Figure 5. Water level time series at Ponte Felice station for the 2005, 2010 and 2012 flood events: Observations (black), open-loop (OL) simulations (blue), and assimilation (ASS) of Static Sensors (red). 
https://doi.org/10.5194/hess-2021-125

Preprint. Discussion started: 8 April 2021

(c) Author(s) 2021. CC BY 4.0 License.

(c) (i)
Hydrology and
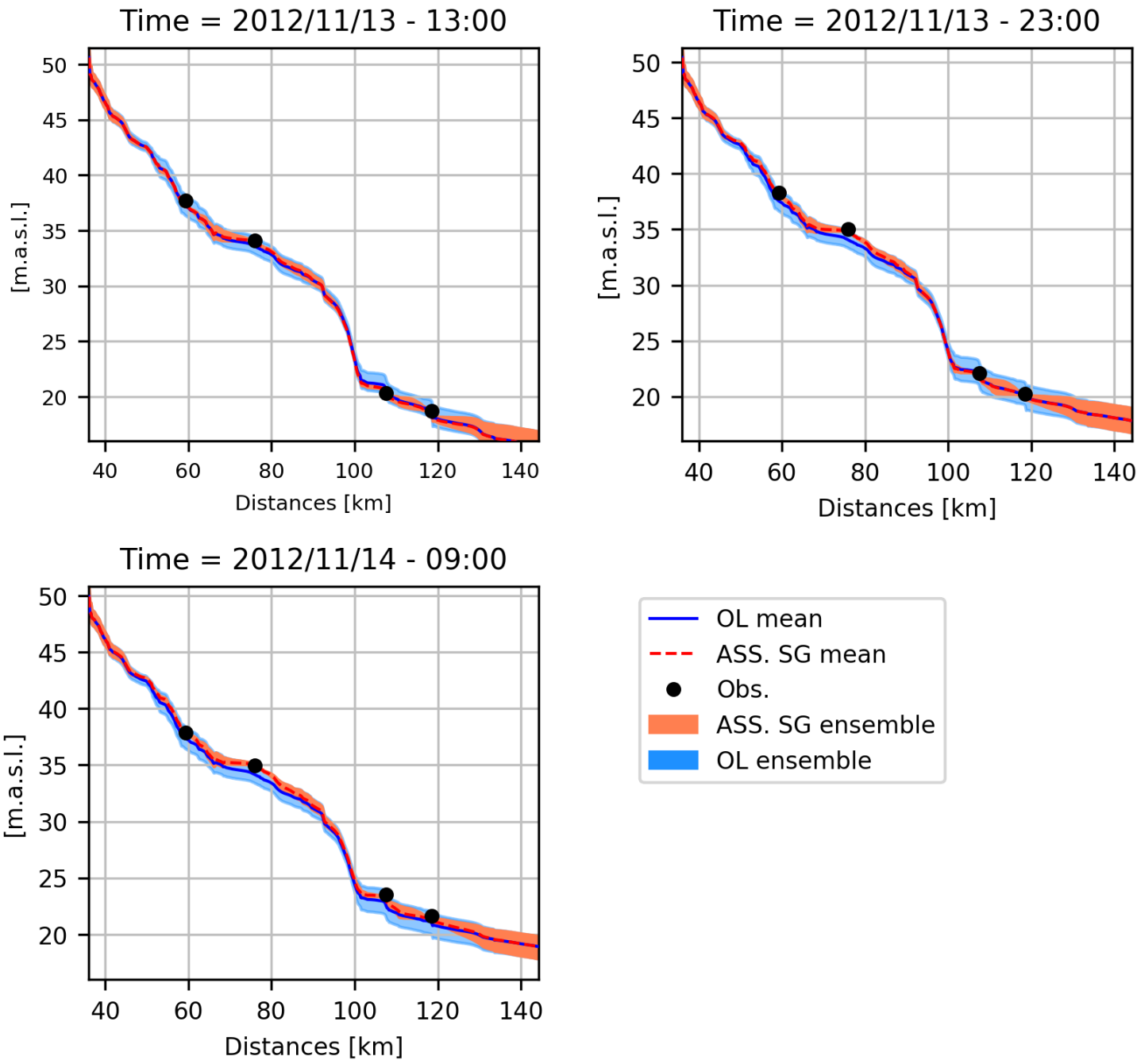

- OL mean

ASS. SG mean

- Obs.

ASS. SG ensemble

OL ensemble

Figure 6. Plot of the channel hydraulic profiles for the open-loop and stage gauges data assimilation simulations for three different time steps. Event: November 2012 


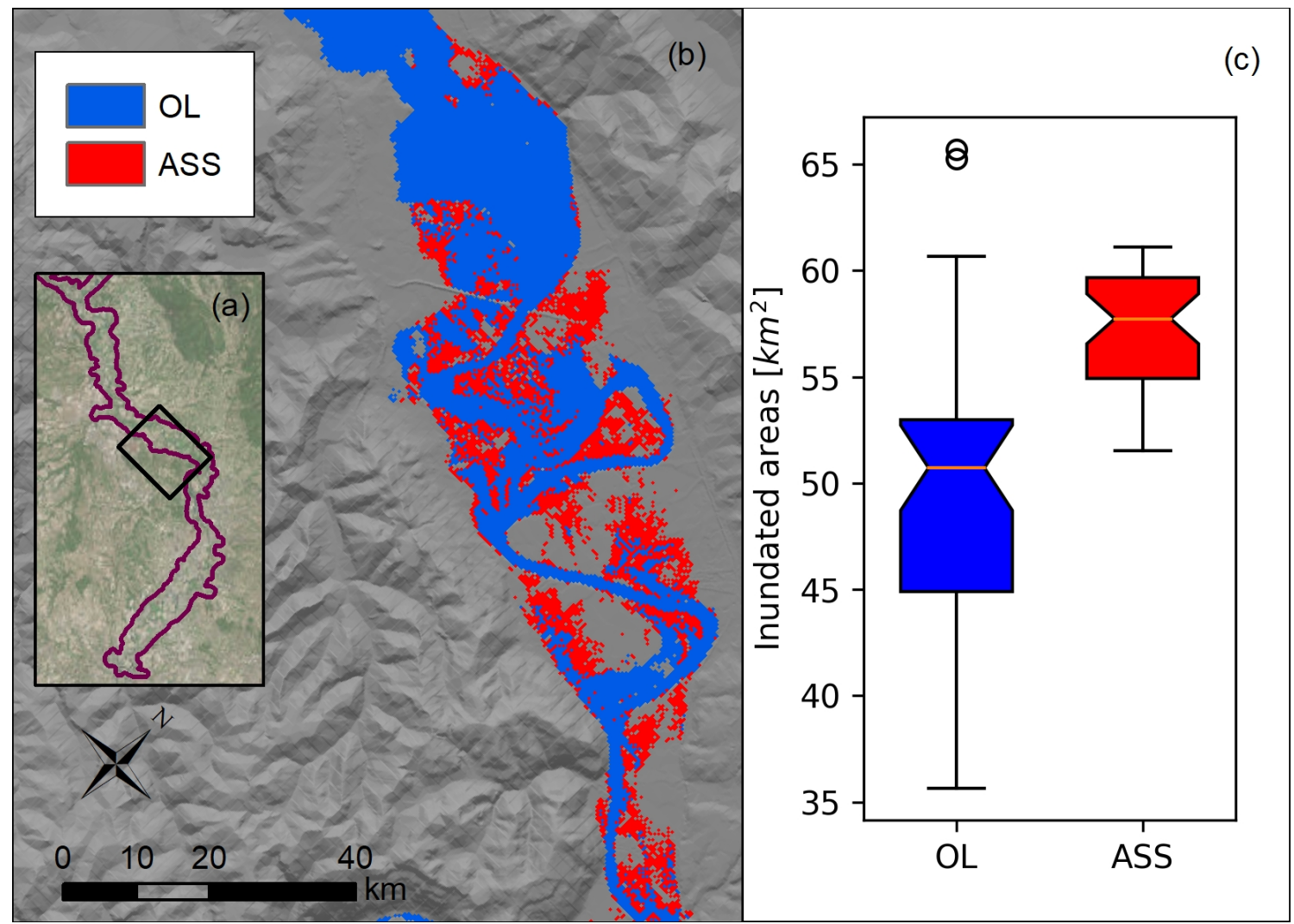

Figure 7. (a)Location of Figure 7(b) area compared to the extension of the computational domain (in purple). (b) Flood extension related to the average water levels for open-loop (OL) and stage observations assimilation (ASS SG) at the time of the Satellite Image acquisition. Note that OL flood extension includes also ASS SG flood extension. (c) Boxplot of the flood extension considering each element of the two ensembles. Event: November 2012 
https://doi.org/10.5194/hess-2021-125

Preprint. Discussion started: 8 April 2021

(c) Author(s) 2021. CC BY 4.0 License.
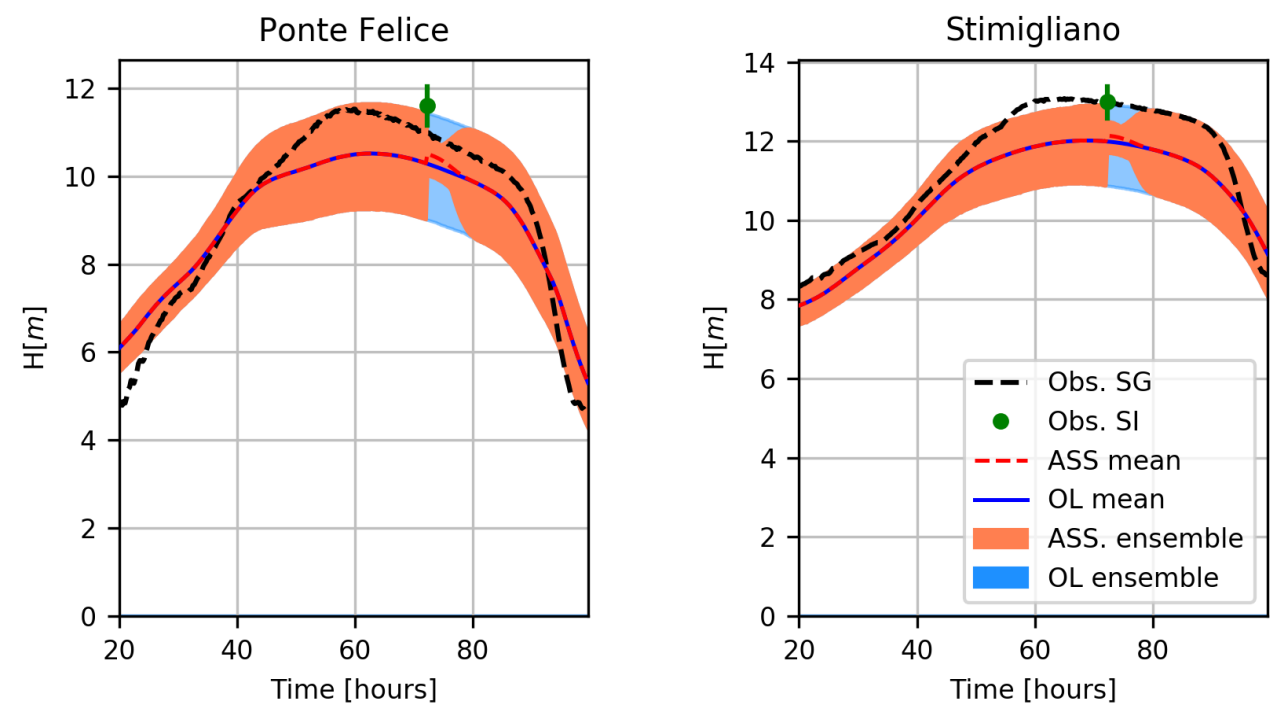

Figure 8. Water level time series at Ponte Felice and Stimigliano stations for the 2012 flood event: Observations (black), open-loop simulations (blue), and assimilation of the indirect observations from the Satellite image (red). 


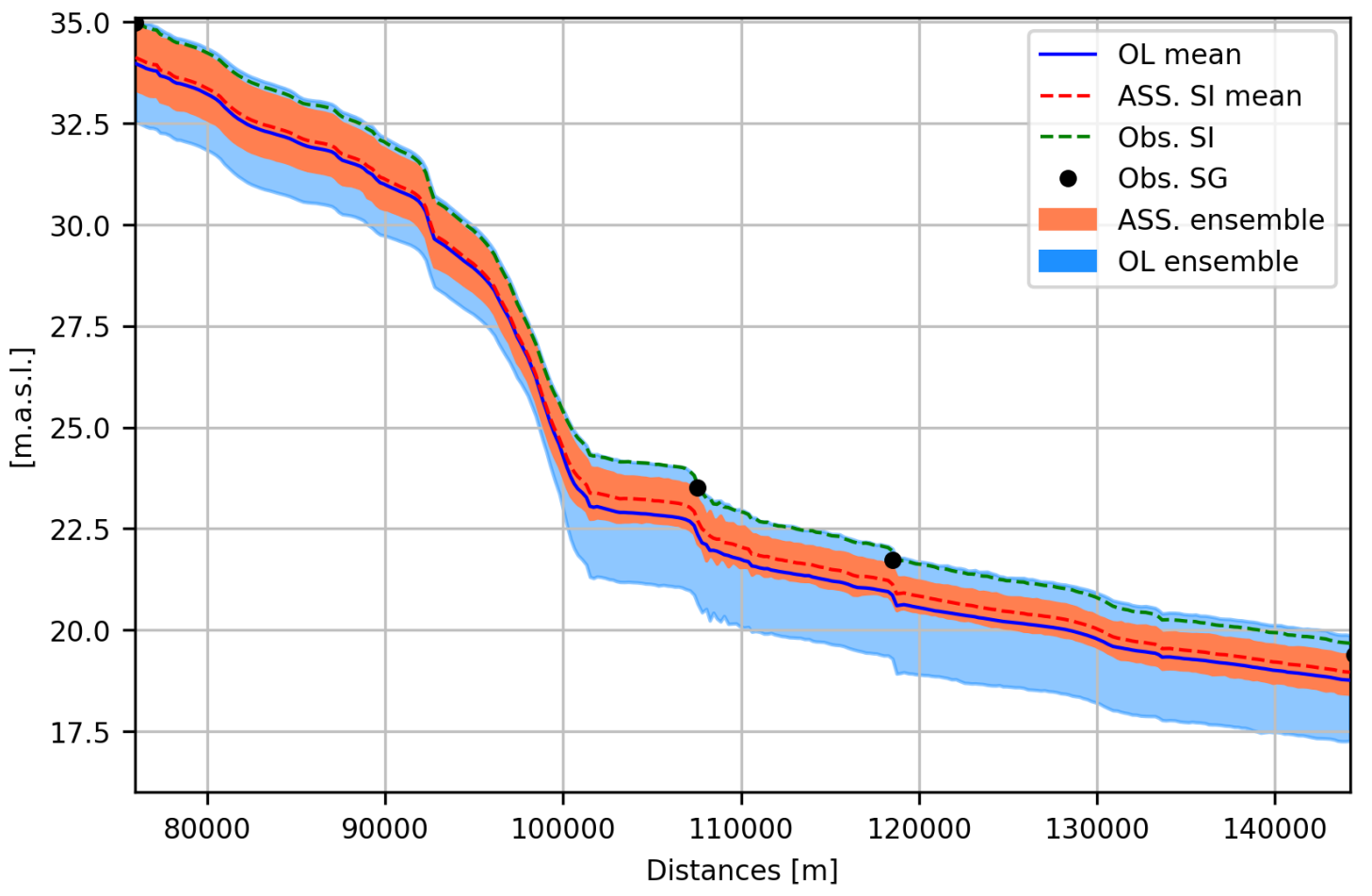

Figure 9. Plot of the channel hydraulic profiles for the open-loop and satellite image data assimilation simulations at the SI acquisition time. Event: November 2012 


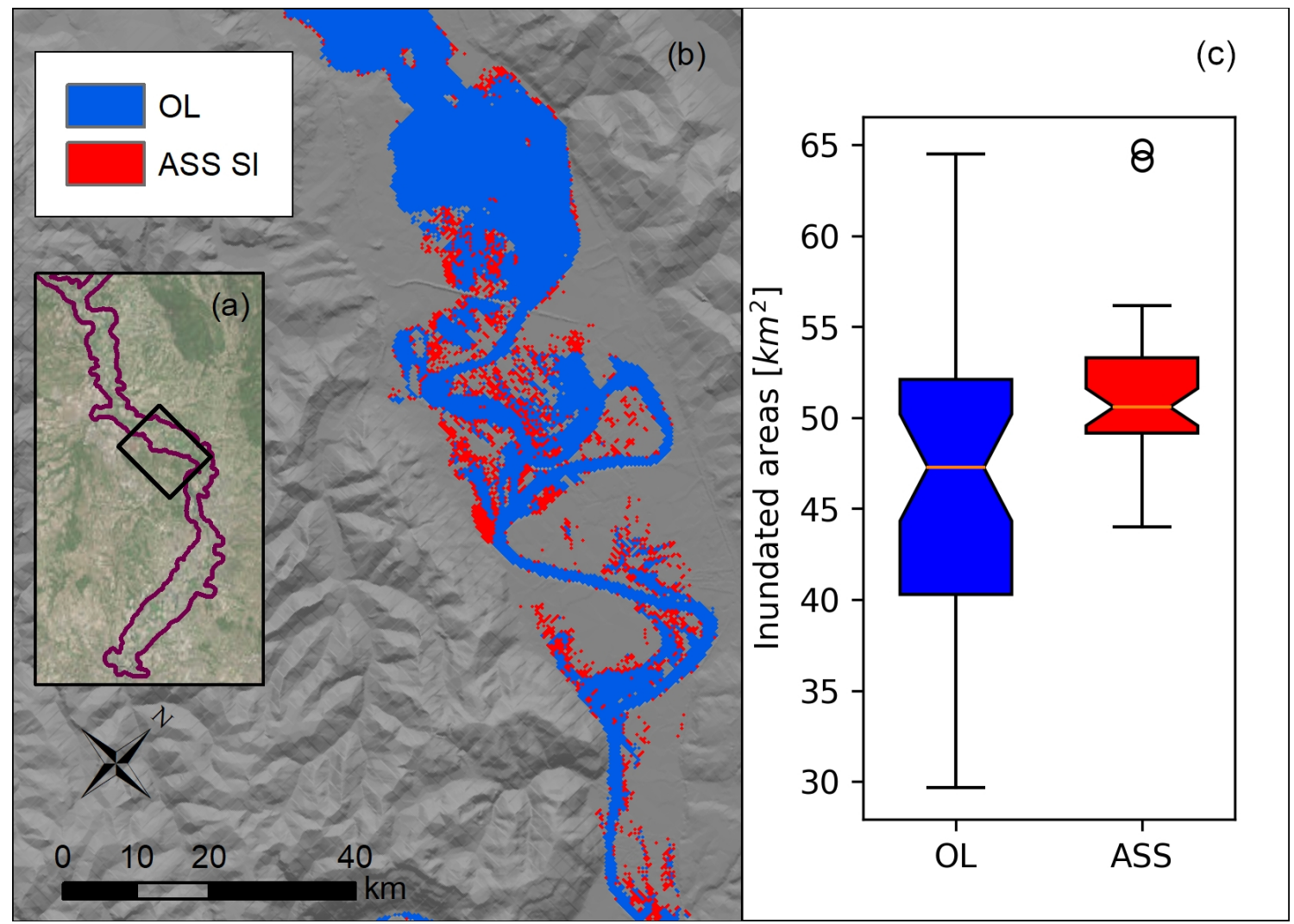

Figure 10. (a)Location of Figure 10(b) area compared to the extension of the computational domain (in purple). (b) Flood extension related to the average water levels for open-loop (OL) and assimilation of the satellite image (ASS SI) at the time of the Satellite Image acquisition. Note that OL flood extension includes also ASS SI flood extension. (c) Boxplot of the flood extension considering each element of the two ensembles. Event: November 2012 


\section{Ponte Felice}
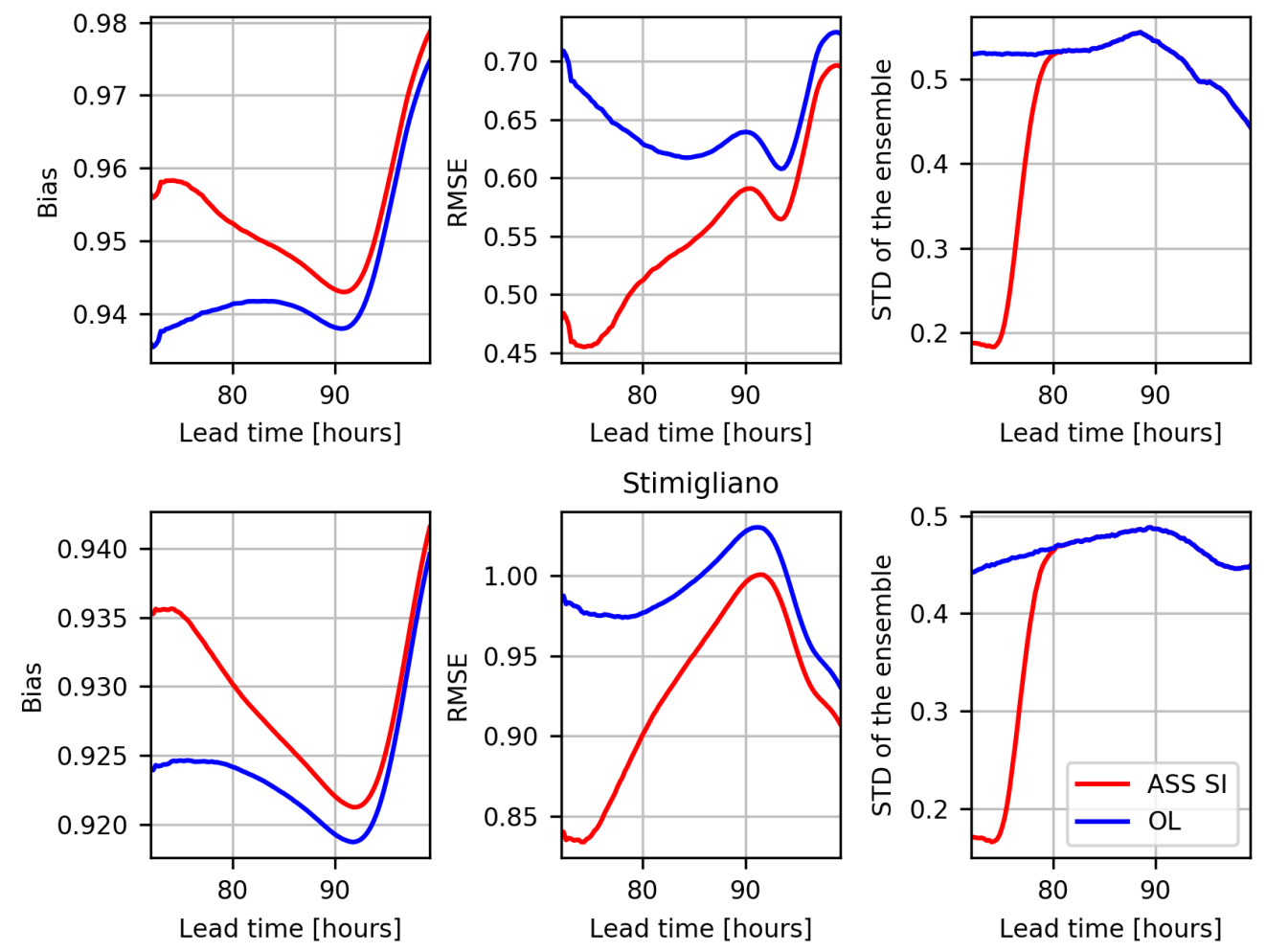

Figure 11. Performance indexes (Bias, RMSE and variance of the ensemble spread) with the lead time after the acquisition time of the SI observation. Event: November 2012 
https://doi.org/10.5194/hess-2021-125

Preprint. Discussion started: 8 April 2021

(c) Author(s) 2021. CC BY 4.0 License.
Hydrology and Earth System Sciences Discussions
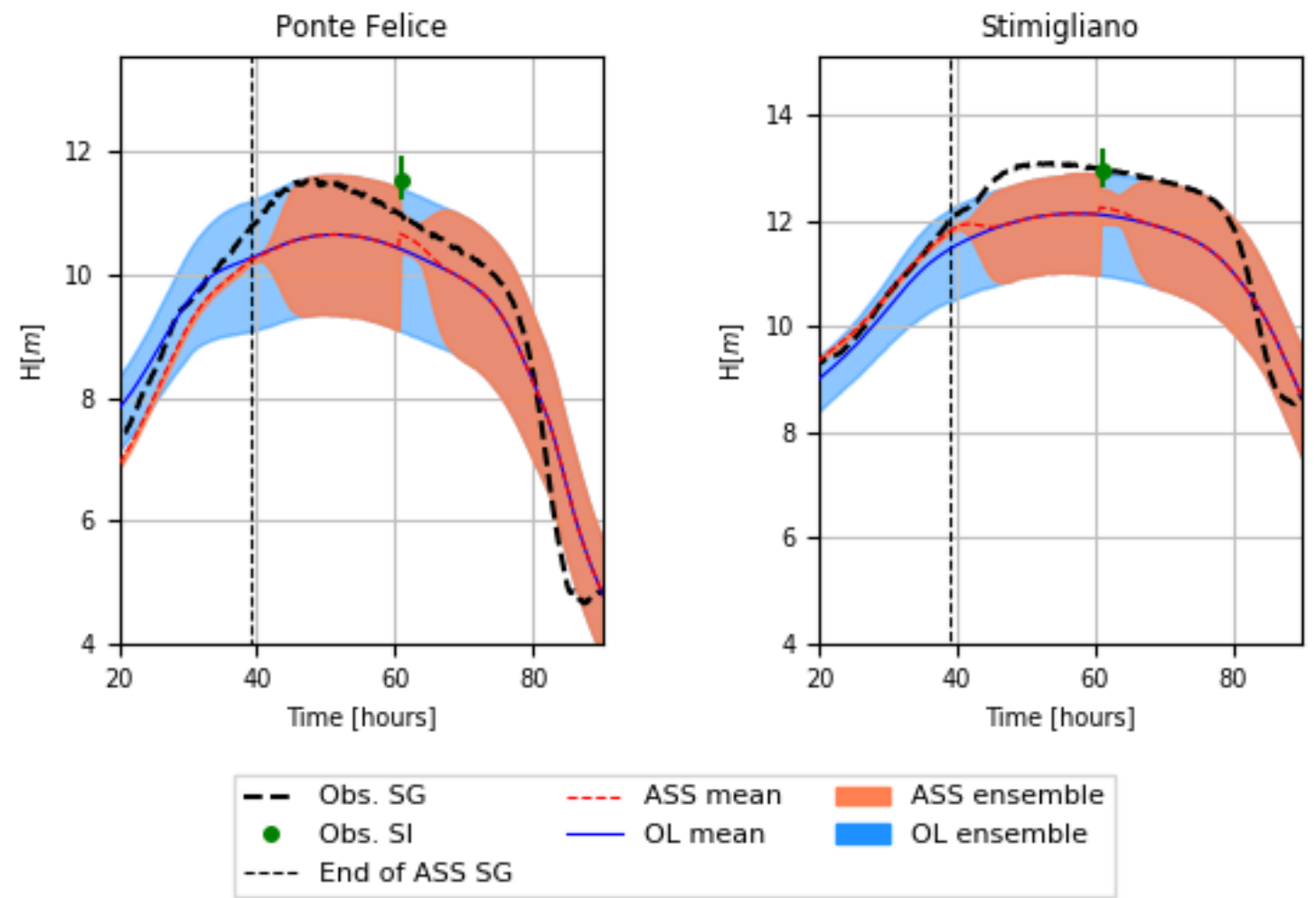

Figure 12. Water level time series at Ponte Felice and Stimigliano stations for the 2012 flood event: Observations (black), open-loop simulations (blue), and assimilation of the indirect observations from both stage gauges and the satellite image (red) 
https://doi.org/10.5194/hess-2021-125

Preprint. Discussion started: 8 April 2021

(c) Author(s) 2021. CC BY 4.0 License.

\section{(c) (1)}

Hydrology and
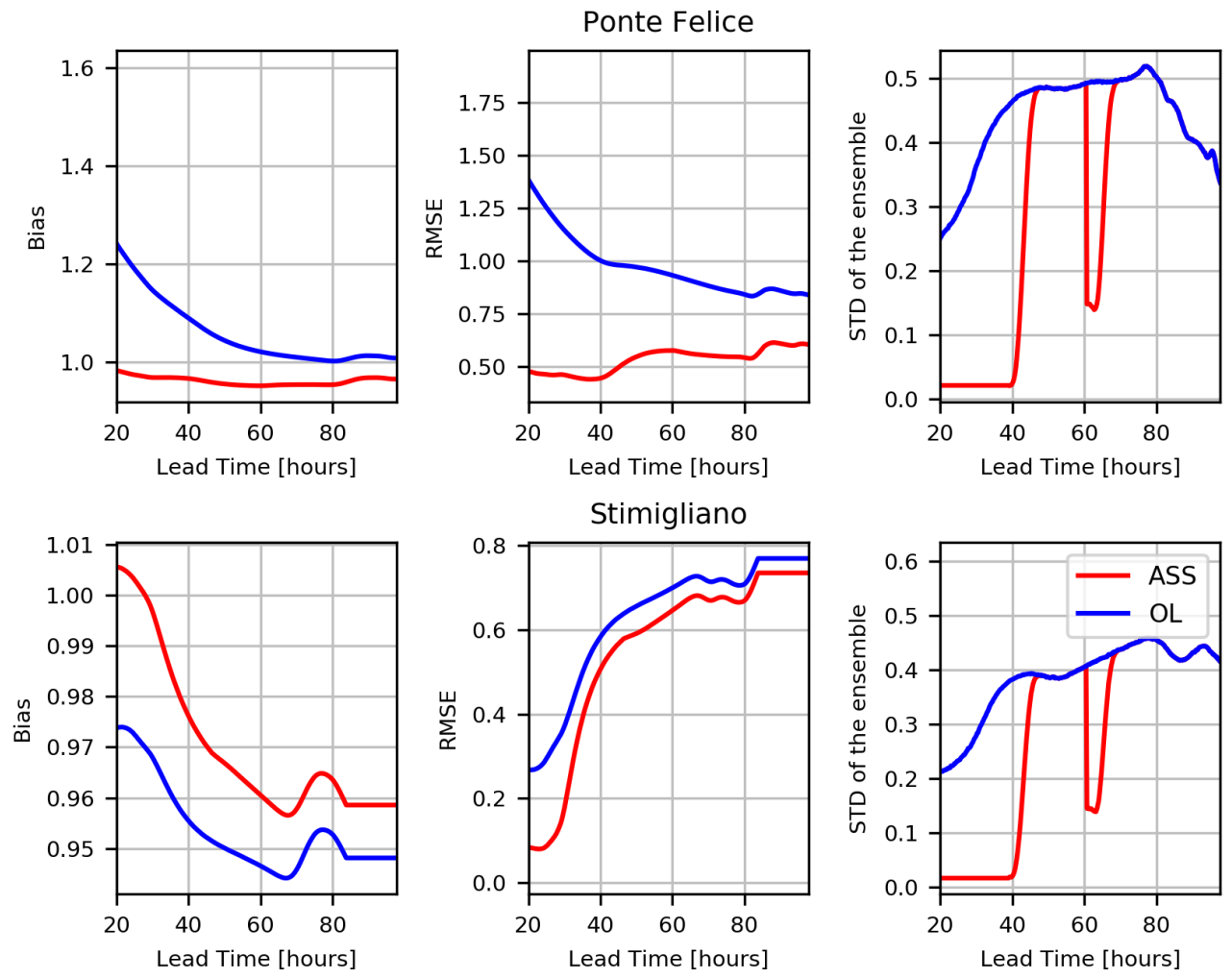

Figure 13. Performance indexes (Bias, RMSE and variance of the ensemble amplitude) with the lead time in cases of OL and assimilation of both SI and SG. Event: November 2012 